\title{
Innovative Strategies for Enhancing Topical and Transdermal Drug Delivery
}

\author{
D.I.J. Morrow, P.A. McCarron, A.D. Woolfson and R.F. Donnelly*
}

School of Pharmacy, Queen's University Belfast, Medical Biology Centre, 97 Lisburn Road, Belfast BT9 7BL, UK

\begin{abstract}
Abstact: Historically, the skin was thought to be a simple homogenous barrier. However, it is now known to be a highly specialised organ, and plays a key role in homeostasis. The protective properties of the skin are provided by the outermost layer, the epidermis, which safeguards against chemical, microbial, and physical attack. The exceptional barrier properties of the skin result in it being a challenging route for the delivery of therapeutic agents. This article reviews strategies developed to enhance the skin penetration of drugs, ranging from conventional approaches, for example the use of chemical penetration enhancers to those in early-stage development, such as microscissioning.
\end{abstract}

Keywords: Transdermal delivery, stratum corneum, penetration pathways, skin penetration.

\section{INTRODUCTION}

The application of medicaments to the skin can be dated back many thousands of years. The ancient Greeks applied a mixture of water, olive oil and lead oxide as a balm to the skin. Lead oxide has astringent properties, and olive oil may act as an occlusive barrier, moisturising the skin [1]. Up until the end of the $19^{\text {th }}$ century, the skin was widely regarded as being an impermeable barrier, even to the penetration of gases [2]. However, in 1893 Bourget and collaborators demonstrated that acute rheumatoid arthritis could be treated with topical salicylic acid [3]. In the early twentieth century it was recognised that more lipophilic agents had increased skin permeability [4]. The barrier properties of the skin were attributed to the outermost layers in 1919 [5]. Until the mid $20^{\text {th }}$ century there was much debate as to which layer of the epidermis was responsible for the permeability barrier. In 1953, Blank [6] employed Wolf's tape stripping technique [7] to assess water permeability of full thickness skin. Water loss remained almost normal until the lowest part of the stratum corneum had been removed, indicating that this layer was the principal permeability barrier. Scheuplein and coworkers thoroughly investigated skin permeability to a wide range of substances in vitro $[2,8,9]$. They modelled skin as a 3-layer laminate of stratum corneum, epidermis and dermis, with drug permeation driven by Fickian diffusion. By digesting the epidermal layer, stratum corneum was separated from the lower layers of the skin, and was determined to be the principal barrier for drug flux.

Until the mid $20^{\text {th }}$ century, physicians prescribed topical preparations solely for the treatment of skin diseases. During World War II, angina attacks were observed to be less frequent amongst munitions employees working with nitroglycerin [10]. Subsequently, in 1954, nitroglycerin ointment was introduced for the management of angina [3]. This was the first commercial topical preparation specifically developed to treat a systemic disease. Thirty years later in the early 1980's, the FDA approved the first transdermal

*Address correspondence to this author at the School of Pharmacy, Queens University Belfast, Medical Biology Centre, 97 Lisburn Road, Belfast, BT9 7BL, UK; Tel: +44 (0) 2890972 251; Fax: +44 (0) 2890247 794;

E-mail: r.donnelly@qub.ac.uk patches; containing scopolamine for the prevention of motion sickness [11], and a patch system releasing nitroglycerin for the prevention of angina. Subsequently, patches containing clonidine, fentanyl, buprenorphine, levonorgestrel, lidocaine, norethisterone, estradiol, oxybutynin, testosterone and nicotine have received approval [11-13]. Transdermal products containing granisetron, human growth hormone, insulin, parathyroid hormone and rotigotine are currently undergoing clinical trials [11].

The majority of licensed preparations applied to the skin are aimed at delivering the drug for a local, rather than a systemic, action. These preparations tend to be relatively simple semi-solids such as creams, gels and ointments. Therapeutic categories include anaesthetics, anti-acne drugs, antimicrobials, corticosteroids, cytotoxics, retinoids, vitamin D analogues and phototherapy [13]. Over the past 25 years there has been increasing interest in transdermal drug delivery. A Pubmed search for 'transdermal' in the year 1990 revealed 295 hits, compared to 947 hits in 2006. Between 1995 and 2002, the US transdermal market doubled from US $\$ 1.5$ billion to over US $\$ 3$ billion, and, it is predicted that in 2008 , the market for transdermal systems will reach US $\$ 4.5$ billion [14].

This review describes the barrier properties of the skin, how drugs penetrate the skin and the techniques that have been used to enhance drug penetration across skin.

\section{THE stratum corneum BARRIER}

The stratum corneum, or horny layer, is the outermost layer of the skin and has been identified as the principal barrier for penetration of most drugs [15]. The horny layer represents the final stage of epidermal cell differentiation. The thickness of this layer is typically $10 \mu \mathrm{m}$, but a number of factors, including the degree of hydration and skin location, influence this. For example, the stratum corneum on the palms and soles can be, on average, 400-600 $\mu \mathrm{m}$ thick [15], whilst hydration can result in a 4-fold increase in thickness [16]. The stratum corneum consists of 10-25 rows of dead keratinocytes (corneocytes) embedded in a lipid matrix [15]. The corneocytes are flattened, elongated, dead cells, lacking nuclei and other organelles [12]. The cells are joined together by desmosomes, maintaining the cohesiveness of this layer [17]. The heterogeneous structure of the stratum cor- 
neum is composed of approximately $75-80 \%$ protein, $5-15 \%$ lipid and 5-10\% unidentified on a dry weight basis [18].

The main lipids located in the stratum corneum are ceramides, fatty acids, cholesterol, cholesterol sulphate and sterol/wax esters $[18,19]$. These lipids are arranged in multiple bilayers called lamellae. Phospholipids are largely absent, a unique feature for a mammalian membrane. The ceramides are the largest group of lipids in the stratum corneum, accounting for approximately half of the total lipid mass [20], and are crucial to lipid organisation of the stratum corneum [17]. The brick and mortar model of the stratum corneum was first presented by Michaels et al. [16]. The bricks correspond to parallel plates of dead keratinised corneocytes, and the mortar represents the continuous interstitial lipid matrix (Fig. 1). It is important to note that the corneocytes are not brick shaped, but rather are polygonal, elongated and flat $(0.2-1.5 \mu \mathrm{m}$ thick and $34.0-46.0 \mu \mathrm{m}$ in diameter) [12]. The mortar is not a homogenous matrix, but rather lipids are arranged in the lamellar phase (alternating layers of water and lipid bilayers), with some of the lipid bilayers in the gel or crystalline state [21]. The extracellular matrix is further complicated by the presence of intrinsic and extrinsic proteins such as enzymes. The barrier properties of the stratum corneum have been assigned to the multiple lipid bilayers residing in the intercellular space. These bilayers prevent desiccation of the underlying tissues by inhibiting water loss and limit the penetration of substances from the external environment $[1,19]$.

\section{TARGETING THE SKIN FOR DRUG DELIVERY}

There are 3 principal targets for topical and transdermal drug delivery, the skin surface, the skin itself (epidermis or dermis) or the systemic circulation. The surface of the skin may be a target when considering disinfectants, insect repellents or cosmetics. Targeting the various layers of the skin is termed topical drug delivery and is relevant when the disease state presents within the organ itself. For example, treating neoplasias, inflammatory disorders and microbial infections of the skin [22]. Increasingly, transdermal or percutaneous delivery, whereby the systemic circulation is the principal target, is being considered as an alternative to conventional systemic and oral routes of administration. Advantages and limitations of this drug delivery route are summarised below [1,11,22-25].

\section{Advantages}

Facilitates sustained delivery of drug, achieving a steady-state profile. This reduces the likelihood of peak-associated side effects, and ensures that drug levels are above the minimal therapeutic concentration

- $\quad$ Reduced dosing frequency - (e.g., fentanyl patch provides 72 hour pain relief)

- $\quad$ Avoids $1^{\text {st }}$ pass metabolism

- Avoids variables that affect drug absorption in the gastrointestinal tract, such as $\mathrm{pH}$, enzymatic activity and drug-food interactions

- $\quad$ Convenient, non-invasive means of drug delivery

- Ease of use negates the need for specialised healthcare staff to administer drugs, potentially reducing treatments costs

- Dosage form can be easily removed in the event of toxicity

Provides an alternative route when the patient is unable to take drugs orally; e.g., nauseated and unconscious patients

\section{Limitations}

Patches tend to be relatively complex systems, which are expensive to develop and manufacture

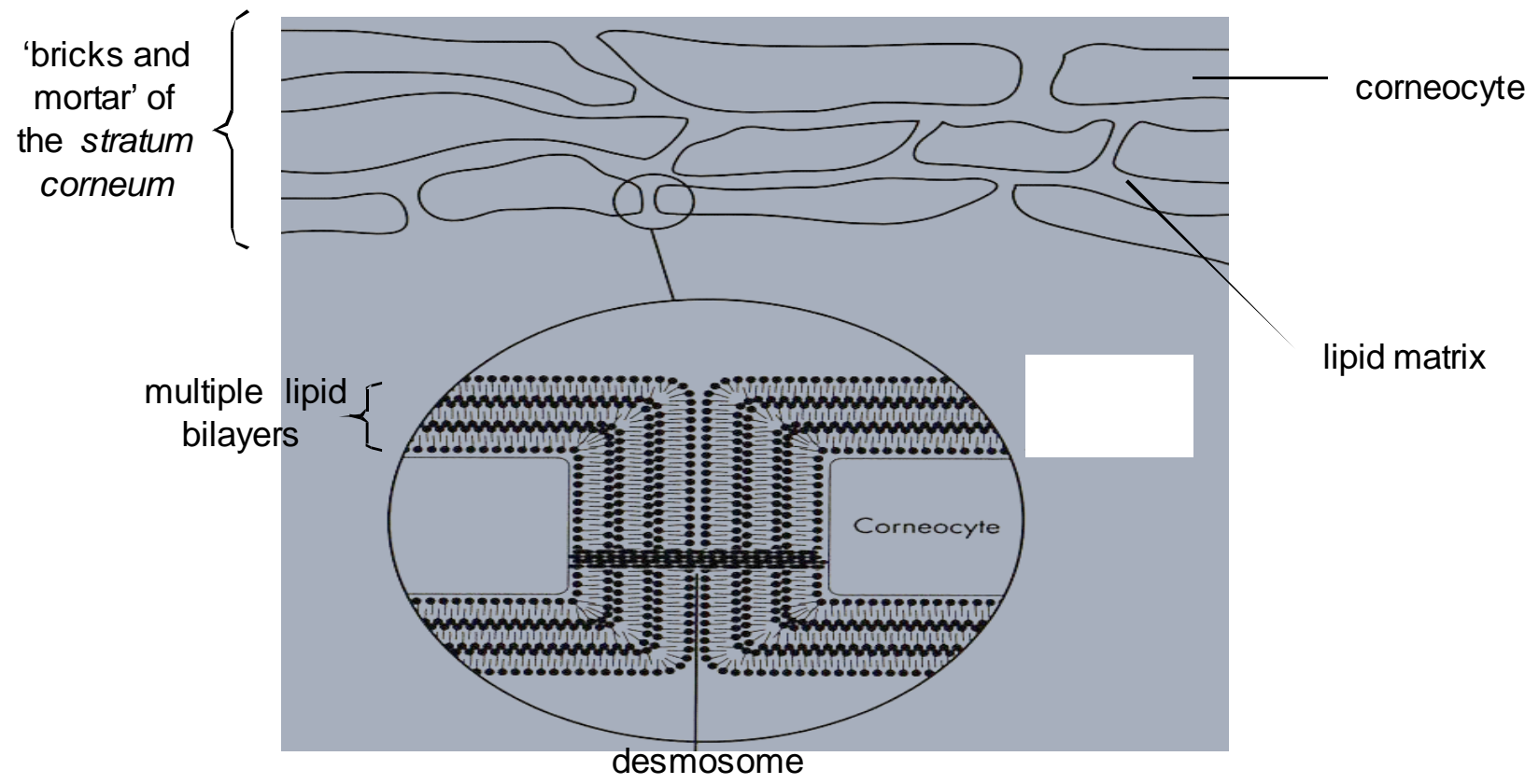

Fig. (1). The 'bricks and mortar' representation of the stratum corneum with alternating lipid bilayers surrounding proteinaceous corneocytes (adapted from [18]). 
Transdermal expertise is limited to a relatively small number of companies

- $\quad$ Suitable drugs are limited by stringent physicochemical factors, including molecular weight, partition coefficient and ionisation

Owing to the excellent barrier properties of the skin, permeated amounts tend to be low. Therefore, only potent drugs are applicable to this administration route

- Some patients may not find patches aesthetically pleasing

- $\quad$ Skin irritation. Drugs and excipients may cause sensitisation, reactions such as erythema and oedema

- Misuse of transdermal patches has been associated with serious adverse effects and even death

\section{DRUG PENETRATION PATHWAYS}

There are critically 3 ways in which a drug molecule can cross the intact stratum corneum: via skin appendages (shunt routes); through the intercellular lipid domains; or by a transcellular route (Fig. 2). A particular drug is likely to permeate by a combination of these routes, with the relative contributions of these pathways to the gross flux governed by the physicochemical properties of the molecule.

\section{The Appendgeal Route}

Skin appendages provide a continuous channel directly across the stratum corneum barrier. However, their influence on drug penetration is hindered by a number of factors. The surface area occupied by hair follicles and sweat ducts is small (typically $0.1 \%$ of skins surface area), therefore limiting the area available for direct contact of the applied drug formulation. Sweat ducts are either empty or actively secreting an aqueous salt solution. Although an aqueous pathway across the skin is considered desirable for many drugs, permeation may be limited as sweat is travelling against the diffusion pathway of the permeant. Sebaceous glands are filled with a lipid rich sebum, which may present a barrier to hydrophilic drugs.

It is been suggested that the shunt route is frequently the dominant pathway shortly after application of the vehicle [2]. Once steady-state diffusion has been established, transepithelial routes become more important [8]. Although the contribution of the appendgeal route is generally considered to have little influence on flux, it has been proposed that this route may be important for large polar molecules and ions [27].

\section{Transcellular Route}

Drugs entering the skin via the transcellular route pass through corneocytes. Corneocytes, containing highly hydrated keratin, provide an aqueous environment for which hydrophilic drugs can pass. The cells are surrounded by a lipid envelope which connects the cells to the interstitial lipids. Separating keratinised skin cells are multiple lipid bilayers; there are estimated to be up to 20 such lamellae between each corneocyte [28]. Therefore, the diffusion pathway for a drug via the transcellular route requires a number of partitioning and diffusion steps. After partitioning into and diffusing through the relatively aqueous corneocytes, the permeant must partition into the surrounding lipid envelope, and subsequently partition in and out of the multiple lipid bilayers separating corneocytes [19]. The physicochemical properties of the permeant will strongly influence whether the transcellular pathway is the predominate route taken. In particular, the relative ability to partition in and out of each skin phase is important. The transcellular pathway is, however, thought to be the predominant pathway for highly hydrophilic drugs during steady-state flux [18].

\section{Intercellular Route}

The intercellular pathway involves drug diffusing through the continuous lipid matrix. This route is a significant obstacle for 2 reasons. Firstly, recalling the 'bricks and mortar'

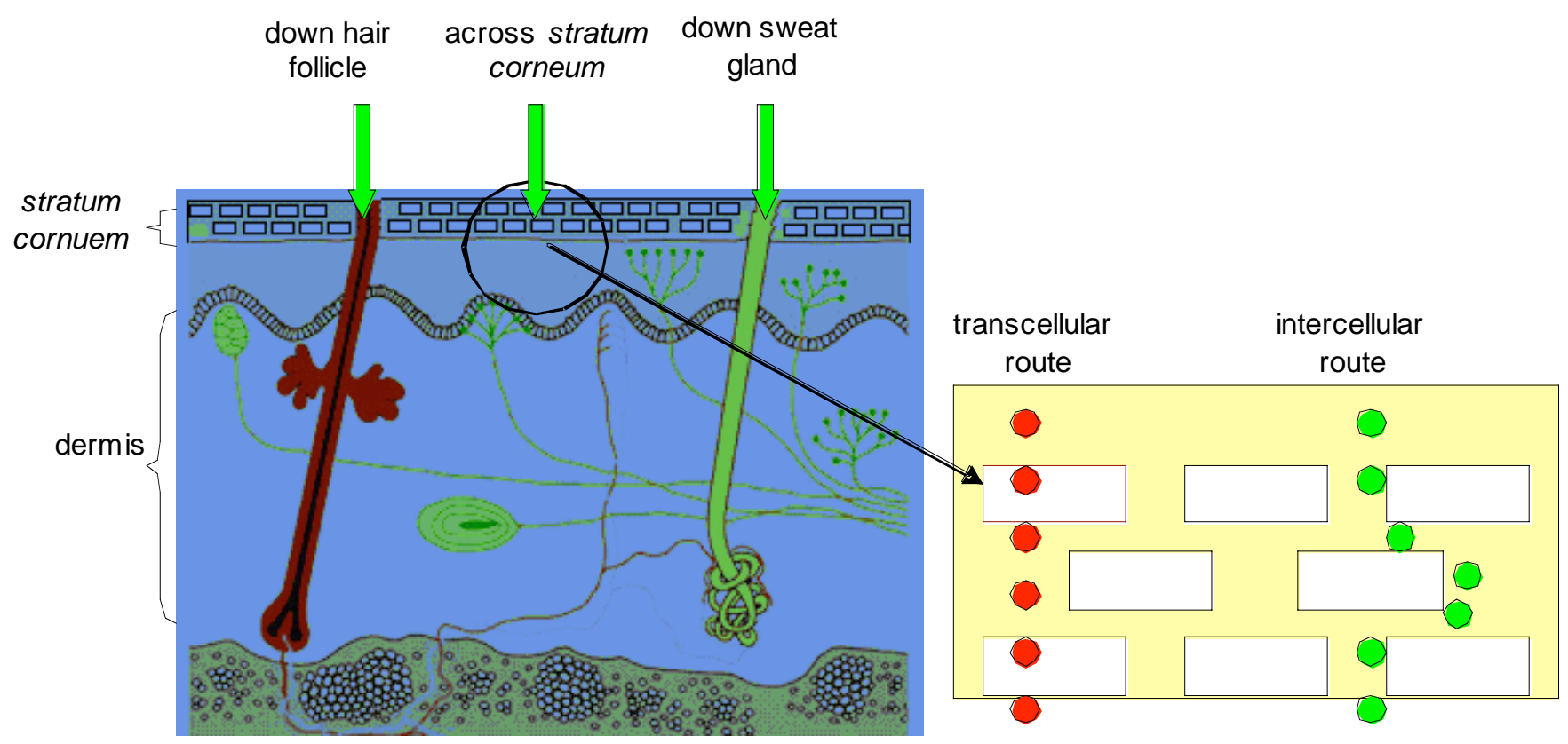

Fig. (2). Drug penetration pathways across skin (adapted from [26]). 
model of the stratum corneum, the interdigitating nature of the corneocytes yields a tortuous pathway for intercellular drug permeation, which is in contrast to the relatively direct path of the transcellular route. It has been estimated that water has 50 times further to travel by the intercellular pathway, than the direct thickness of the horny layer [29]. Secondly, the intercellular domain is a region of alternating structured bilayers. Consequently, a drug must sequentially partition into, and diffuse through repeated aqueous and lipid domains. This route is generally accepted as the most common path for small uncharged molecules penetrating the skin $[18,30]$.

\section{MODULATION OF TOPICAL AND TRANSDERMAL PENETRATION}

The stratum corneum is the principal barrier to drug permeation across the skin. Consequently, there has been a concerted effort to investigate and develop novel strategies of maximising the amount of permeant crossing this barrier. Innovative approaches focus on altering the drug-vehicle interaction to enhance partitioning into the stratum corneum, or modifying the structure of the stratum corneum to make it less resistance to drug diffusion. Alternatively, energy-driven methods have been employed to propel drugs across the skin (Fig. 3).

\section{THERMODYNAMIC ACTIVITY AND SUPERSATU- RATION}

Steady-state flux of a drug through skin is described by Equation 1.

$$
\frac{d M}{d t}=\frac{D P C_{v}}{h}
$$

where $d M / d t$ is the cumulative amount of permeant passing per unit area of membrane (flux), $D$ is the diffusion coeffi- cient, $C_{v}$ is the concentration of the drug in the vehicle, $P$ is the partition co-efficient between the membrane and the vehicle and $h$ is membrane thickness. Higuchi [31] rewrote this equation in terms of thermodynamic activities (Equation 2).

$\frac{d M}{d t}=\frac{a D}{\gamma h}$

where $a$ is the thermodynamic activity of the permeant and $\gamma$ is the effective activity coefficient in the membrane. The maximum flux of a drug across a membrane occurs when the drug is at its highest thermodynamic activity. At saturation, equilibrium exists between the solid and liquid phase and activity equals 1 [32]. Therefore, all vehicles that contain a finely ground suspension exist as saturated solutions of the drug [33]. Activity can exceed unity when supersaturated systems are formed, although such systems are inherently unstable. The degree of saturation of the solution is calculated by dividing the drug concentration in the prepared solution by the saturated solubility in the same solvent mix.

The most common method of creating a supersaturated system is the co-solvent method described by Poulson et al. [34]. Saturated solutions of co-solvent mixture are mixed with a poor solvent to create a supersaturated system [3537]. Megrab et al. [38] investigated estradiol penetration across human skin and a silicone membrane. Supersaturated systems (up to 18 degrees of saturation) were prepared by adding aqueous solutions to a saturated solution of estradiol in a propylene glycol/water (60:40) mix. Using the supersaturated system, drug flux was found to increase 13 and 9.3 times through excised human skin and silicone membranes, respectively.

Supersaturated systems can also be obtained, by evaporation of a volatile co-solvent. Moser et al. [39] prepared formulations containing the lipophilic drug, lavendustin, dis-

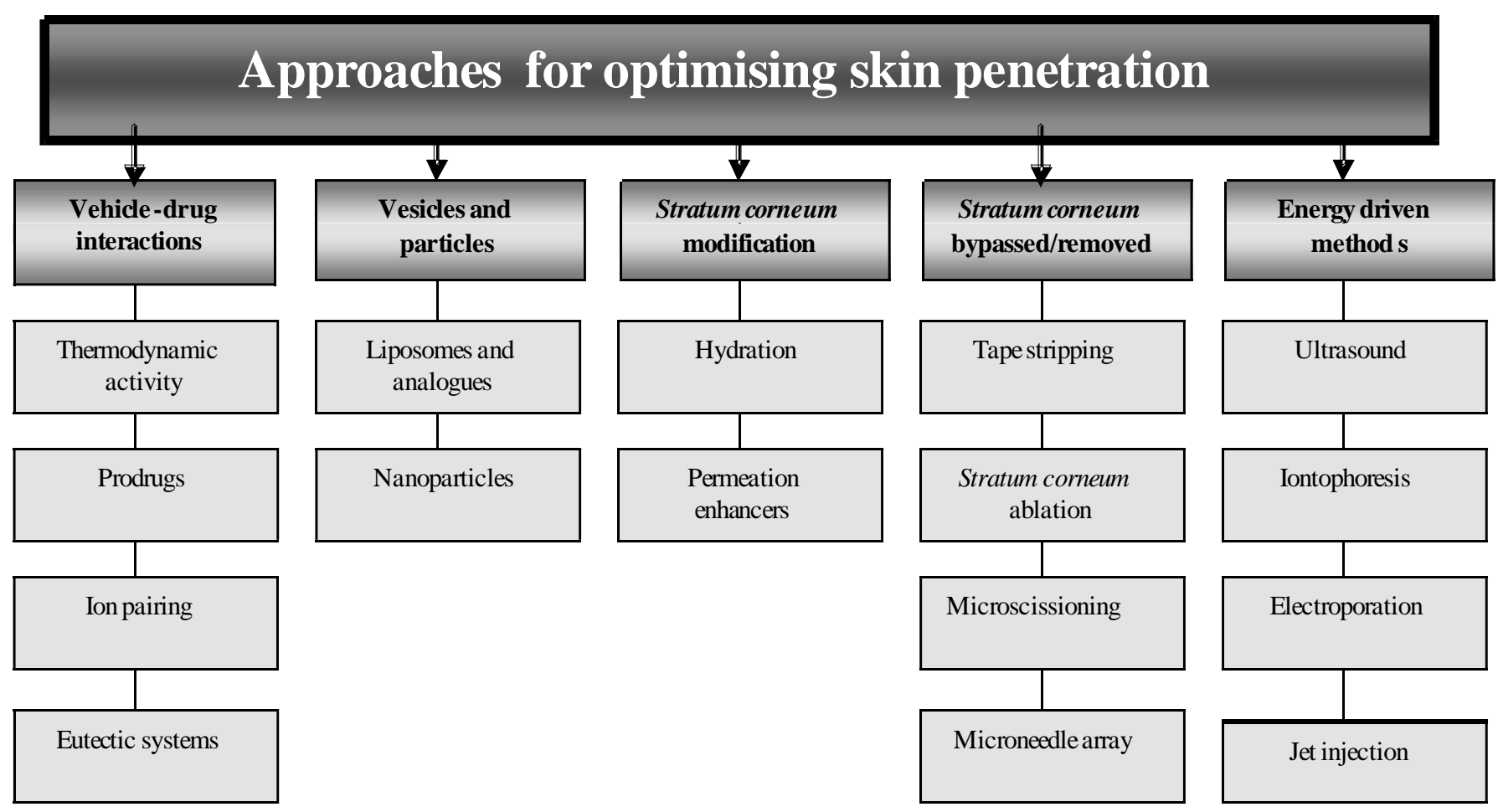

Fig. (3). Summary of methods used to optimise topical and transdermal drug delivery. 
solved in an ethanol-propylene glycol mix. In contrast to the co-solvent procedure described above, this formulation becomes supersaturated due to ethanol evaporation during the course of the experiment. The formulation was said to be stable for up to 8 hours at approximately 2 degrees of saturation, and the permeation rate of the supersaturated system across excised pigskin was approximately twice that of a saturated vehicle. Supersaturated systems can also be prepared by cooling a heated saturated solution down to skin temperature [40] or by moisture from the skin absorbing into a formulation, and acting as an antisolvent [41].

By tailoring the vehicle to maximise the thermodynamic activity of the drug, significant enhancement in drug flux can be achieved. This strategy is non-invasive and inexpensive to implement. However, supersaturated systems are, by their nature, thermodynamically unstable, and material in excess of the solubility limit will crystallise out. To inhibit drug crystallisation, and hence maintain the supersaturated state, various polymers have been used as antinucleants [35,36,38,42-44]. These agents are thought to adsorb onto initial crystals, preventing further crystal growth $[38,45]$. The use of polyvinylpyrrolidone (PVP) as an antinucleating agent was successfully demonstrated by Ma et al. [45]. Crystallisation of a steroid drug formulated in a matrix-type patch containing PVP, was delayed for a further 6 months compared to a patch void of an antinucleant.

\section{PRODRUGS}

Prodrugs are compounds which are usually, but not always, inactive in their parent form. Following administration, the parent drug is chemically transformed to active metabolites, which are largely responsible for exerting the pharmacological effect [46]. In terms of topical and transdermal delivery, the physicochemical characteristics of a drug can be optimised by altering its chemical structure. The aim of this is to develop an entity with improved partitioning and diffusion characteristics. Generally, prodrugs are designed to enhance the lipophilicity of the parent drug, thus increasing skin partitioning. The most common prodrug strategy is to covalently link an active drug with an inactive moiety via an ester bond [46]. Following administration, non-specific skin esterases cleave the active drug. The inactive moiety should be non-toxic and rapidly eliminated from the body.

The prodrug approach has been used to increase delivery of a range of drugs across the skin, including 6mercaptopurine [47], 5-fluorouracil [48], naproxen [49,50]; kepoprofin [50]; diclofenac [50]; ketoralac [51], captopril [52], cyclosporine [53], buphenorphine [54], beta blockers [55], theophylline [56] and 5-aminolevulinic acid [57,58]. Permeation enhancement across skin can vary from negligible to over an order of magnitude. Van den Akker et al. [58] reported no significant increase in penetration of 5aminolevulinic acid esters across mouse skin compared to the parent drug. In contrast, dialkylamnomethyl prodrugs of 6-mercaptopurine were found to have delivery rates up to 27 fold greater than the parent molecule [47]. One of the most successful commercial applications of the prodrug approach has been the use of the steroid ester betamethasone-17valerate. However, as prodrugs are considered to be a new chemical entity, commercial development is generally limited [18].

\section{ION-PAIRS}

Ionised drugs do not readily permeate across human skin, indeed their permeation coefficient has been estimated to be approximately $10^{4}$ times smaller than for the respective noncharged species [59]. The ion-pair strategy involves adding oppositely charged species to a charged drug, forming an ion-pair in which the charges are neutralised. The pair of oppositely charged ions is held together by Coulomb attraction without formation of a covalent bond [60]. The ion-pair should partition and diffuse through the stratum corneum, before dissociating in the viable epidermis, thereby releasing the active drug.

Megwa and coworkers [61] illustrated enhanced penetration of salicylic acid using the ion-pair strategy. A reduction in solution conductivity was observed in equimolar mixtures of salicylic acid and various alkyl amines, indicating ion-pair formation. Permeation experiments using excised human epidermis showed an almost 5-fold enhancement in salicylic acid penetration. Using a silicone membrane, Sarveiya et al. [60] reported a 16-fold increase in steady state flux of ibuprofen using triethylamine as a pairing agent. The authors confirmed ion-pair formation using NMR spectroscopy. The ion-pairing strategy has also been employed to enhance skin penetration of 5-aminolevulic acid [62], diclofenac [63], lidocaine [64], retinoic acid [65] and ondanestron [66].

\section{EUTECTIC MIXTURES}

The steady-state flux of a molecule across a membrane will be directly proportional to the solubility of the drug in the lipid phase of the membrane (assuming sink conditions at one side of the membrane and infinite dose of drug on the other). If a solution is ideal, log (solubility) should be directly related to the reciprocal of the melting point of the drug in a given solvent (Equation 3) [19,67].

$$
\log C p=\frac{C O N S T A N T+\Delta H_{d}}{2.303 R T_{m}}
$$

where, $C_{p}$ is the mole fraction solubility of the drug, $\Delta H_{d}$ is the drug lattice dissociation energy, $R$ the gas constant; and $T_{m}$ the drug melting temperature. Soluble drug is the only physical form that can diffuse. A linear correlation is seen when $\log$ (steady-state flux) is plotted against melting point, indicating that the lower the melting point (greater solubility) the better the penetration [33].

Eutectic mixtures can be used to reduce the melting point of a drug. A binary eutectic is a mixture of 2 components, which do not interact to form a new chemical entity. Instead, at certain ratios, they inhibit the crystallisation process of one another, resulting in a system with a lower melting point than either of the components. The simplest eutectic systems contain two constituents, and are described using a binary phase diagram, depicting compositional changes as a function of temperature. A generic binary phase diagram $(A+B)$ is shown in Fig. (4). If a mixture (X) of $\mathrm{B}(65 \%)$ and $\mathrm{A}$ $(35 \%)$ is heated to $\mathrm{T}_{2}$, then one liquid phase would exist. When cooled, this would continue to be the situation until the temperature dropped to intersect the slope on the phase diagram, termed the liquidus line. Solid B would then pre- 


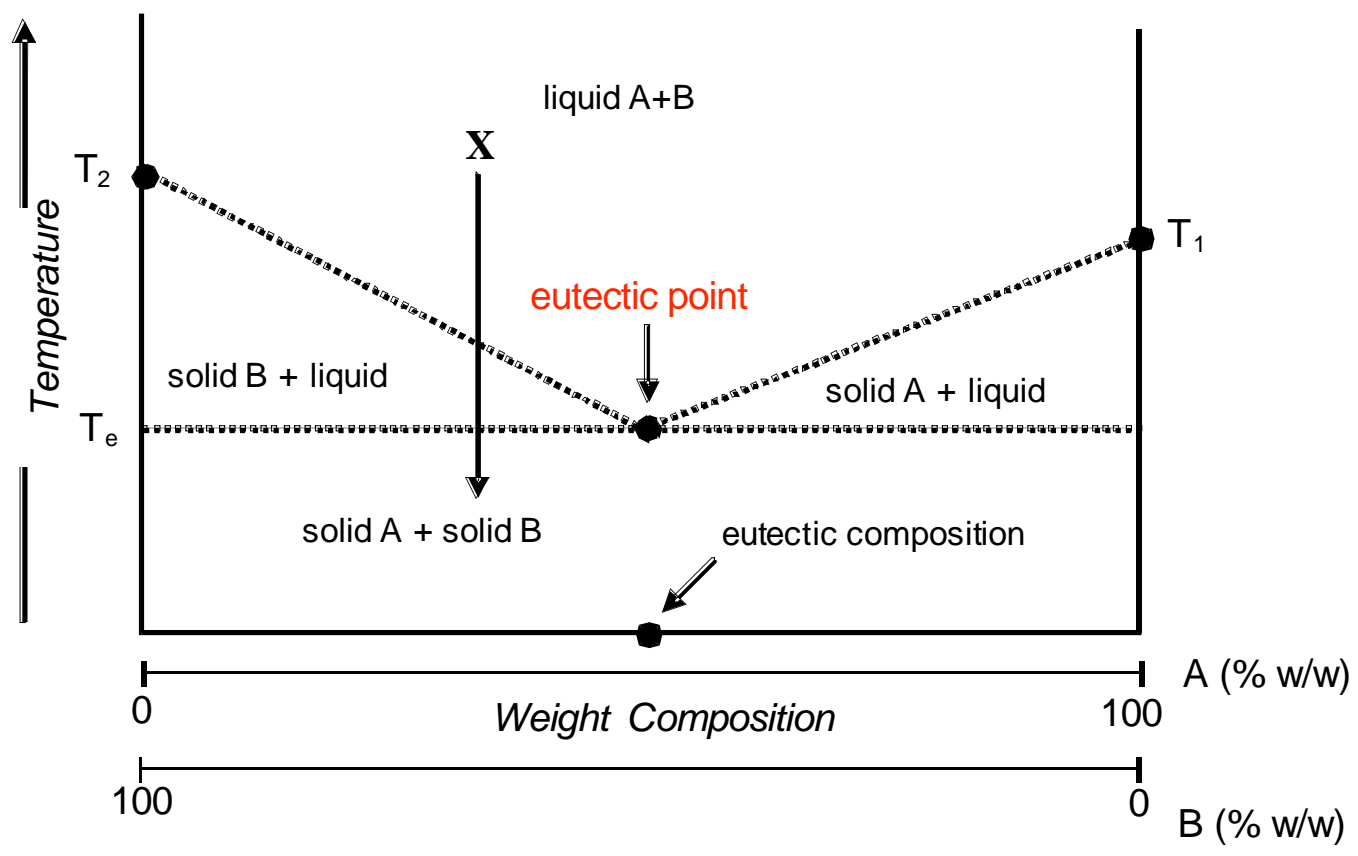

Fig. (4). Phase diagram of a 2 component eutectic system.

cipitate out of solution as the temperature continued to decrease, resulting in a solid dispersion. At the eutectic composition (A 52\%; B 48\%) cooling from $\mathrm{T}_{2}$ progresses in a different manner to $\mathrm{X}$. A liquid at this composition is the only one which, on cooling, would not deposit any pure A or B, but would go from a solution of $\mathrm{A}$ and $\mathrm{B}$ to a solid solution of A and B. Solid solutions are defined as two solids being present as a single crystalline phase, and may be termed substitutional or interstitial [68]. A substitutional solid solution is formed when 1 component takes the place of the other in the crystal lattice to form a mixed crystal. Interstitial solid solutions are formed when 1 component is small enough to fit into spaces between adjacent molecules in a crystal lattice of the other component.

The first commercial topical formulation based on a eutectic mixture was EMLA ${ }^{\circledR}$ cream. The oil-in water-cream formulation consists of a 1:1 eutectic mixture (melting point $18^{\circ} \mathrm{C}$ ) of lidocaine and prilocaine [69]. Having the active components in the liquid state allows direct emulsification of the ingredients without prior dissolution, thus maximising thermodynamic activity of the drugs in the external phase $[18,68]$. One disadvantage associated with EMLA is the delay in analgesia following application [70]. S-caine ${ }^{\circledR}$, is a eutectic mixture of lidocaine $2.5 \%$ and tetracaine $2.5 \%$ [71]. The cream formulation dries and forms a flexible membrane that is easily removed; meaning no occlusion is required. Furthermore, the delivery system has been shown to provide local anaesthesia within 30 minutes of application [72,73]. A 7.8-fold increase in testosterone penetration across full thickness excised mouse skin was reported when the drug was formulated as a eutectic mixture with menthol [74]. The authors suggested that the increase in flux was due to a combination of increased drug solubility and menthol interacting with skin lipids. Eutectic mixtures have also been employed to enhance topical delivery of ibuprofen [68] and propranolol [75].

\section{LIPOSOMES AND ANALOGUES}

Liposomes are thermodynamically stable vesicles composed of one or more concentric lipid bilayers [76]. Liposomes have 2 compartments, an aqueous central core, and a lipophilic region within the lipid bilayer. Hydrophilic drugs can be incorporated into the inner aqueous volume, whilst hydrophobic molecules can be entrapped in the lipid bilayers (Fig. 5). Conventional liposomes are composed of phospholipid, with or without cholesterol. The most common phospholipid is phoshatidylcholine from soybean or egg yolk, with cholesterol often used to stabilise the system [77]. As well as traditional liposomes, a range of structurally similar vesicles have been developed, including transfersomes, ethosomes and niosomes.

\section{Conventional Lipsomes}

Conventional liposomes can be prepared in several ways [79]. Most frequently a film hydration method is employed [18], where a thin layer of lipid is deposited on the walls of a container by evaporation of a volatile solvent. An aqueous solution containing the drug to be entrapped is added at a temperature above the phase transition temperature of the lipids, resulting in formation of multilamellar vesicles (MLV). These systems contain several lipid bilayers surrounding an aqueous core. Further processing by sonication or filter extrusion produces large unilamellar vesicles (LUV, 1-5 $\mu \mathrm{m}$ diameter), or small unilamellar vesicles (SUV, 0.1$0.5 \mu \mathrm{m}$ diameter).

The mechanism of liposomal action is not completely understood and a number of theories have been proposed. Early studies [80] suggested that intact vesicles penetrate the stratum corneum. Foldvari and coworkers [81] used large MLVs packed with colloidal iron (an electron dense marker) to demonstrate the presence of intact SUVs in the dermis 


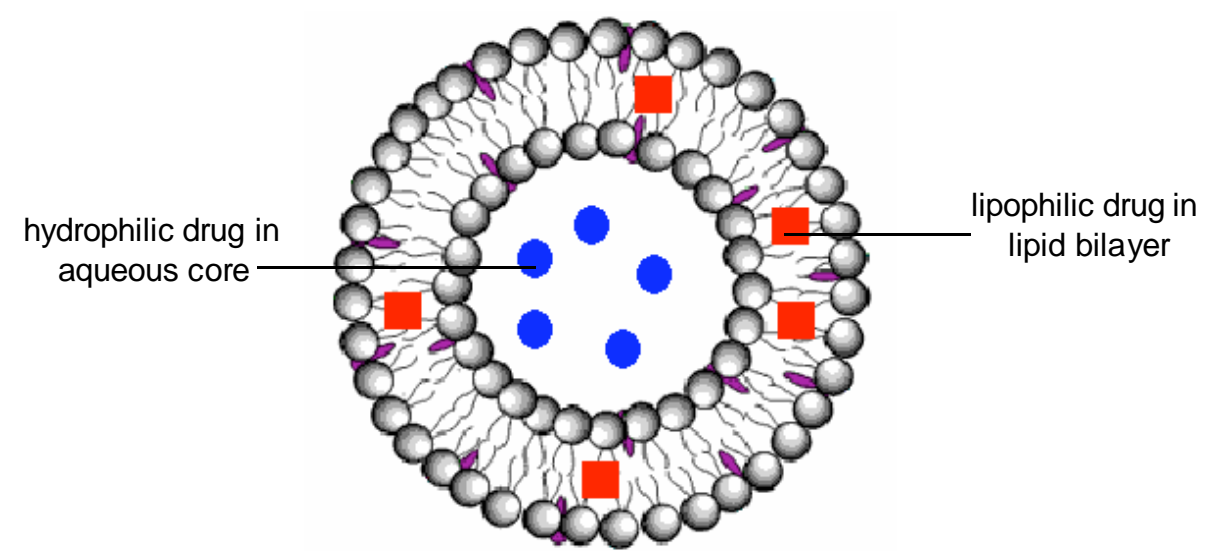

Fig. (5). Distribution of hydrophilic and lipophilic drugs with a liposomal carrier (adapted from [78]).

with electron micrography. The authors proposed that large liposomes may lose external bilayers during penetration, facilitating permeation of smaller vesicles. However, when Du Plessis and collaborators [82], examined the influence of vesicular size on skin deposition of cyclosporin, they found that intermediate sized, rather than small liposomes induced better drug penetration. If liposomes penetrate the skin intact, clearly small vesicles would be expected to permeate better. An alternative explanation was sought when Kirjavainen et al. [83] reported a similar improvement in delivery when a fluorescent marker was incorporated into liposomes and when empty vesicles of similar composition were used to simply pre-treat the skin. The authors proposed that vesicles adsorbed onto, and fused with the skin surface. Thereafter, liposomal lipids act as skin penetration enhancers, disrupting the integrity of the outer layer, and facilitating enhanced drug permeation through it. However, the importance of liposome structure was demonstrated by [84]. The authors reported that liposome components in solution did have an additive influence on drug penetration, but was not the main factor. It was concluded that for optimum skin penetration, lipids and ethanol should be incorporated into vesicles [84]. The transappendgeal route is limited to liposomal targeting into, but not necessarily through, the skin and is not thought to play a significant role in improving liposomal transdermal delivery $[85,86]$.

Mezei and Gulasekharam [80] first demonstrated enhanced topical delivery using liposomes containing triamcinolone acetonide. The authors compared a liposomal lotion and an ointment containing the same drug concentration. The liposomal system was found to deliver 4-5 times more steroid to the epidermis and dermis, with lower levels of drug being delivered systemically. Subsequent work has confirmed that conventional liposomes are a useful means of targeting skin layers, but are generally little or no value as transdermal drug delivery carriers [87-90]. As well as targeting the skin layers, liposomal systems have been shown to target skin appendages. Lieb et al. [91], illustrated follicular targeting using liposomes containing a fluorescent dye (carboxyfluorescein). In contrast, dye formulated in simple aqueous solutions was restricted to the horny layer.

\section{Niosomes}

Niosomes or Non-ionic Surfactant Vesicles (NSV) are formed by the self-assembly of non-ionic surfactants in an aqueous dispersion. The mechanism of action of niosomes is thought to be similar to that described above for conventional liposomes [18]. Although niosomes have advantages in terms of cost, and chemical stability [92] they have been shown to be associated with reduced fluxes compared to conventional liposomes [93].

\section{Transfersomes}

Highly deformable, or elastic, liposomes, termed transfersomes, were first described by Cevc and Blume [94]. As with liposomes, transfersomes are composed of phosholipids, such as phosphatidylcholine, but, in addition, contain a surfactant (10-25\%), such as sodium cholate, deoxycholate, Span 80 , Tween 80 or dipotassium glycyrrhizinate [12,95]. Surfactant molecules act as an 'edge activator', which destabilises the lipid bilayers, conferring greater flexibility to the liposome [18]. Consequently, during deformation, surfactants tend to accumulate at the site of increased stress, due to their propensity for curved structures [85], thus reducing the energy required for changing shape. Transfersomes contain up to $10 \%$ ethanol, with the final aqueous lipid suspension having a total lipid concentration between 5 and $10 \%$ [18]. Preparation methods are similar to those employed with conventional liposomes. The film hydration method is used most commonly [95].

Typically, conventional rigid liposomes are 100-400 nm in diameter and are thought to be too large to fit between intercellular lipid domains of the stratum corneum [77]. U1tra deformable transfersomes are said to be able to squeeze through pores that are $10 \%$ of the vesicle diameter (approximately $20 \mathrm{~nm}$ pore diameter) [94]. Whereas the diffusion gradient is the driving force behind the topical delivery of drugs, the osmotic gradient across the skin is thought to be responsible for driving elastic vesicles [85]. The difference in water content varies from almost $100 \%$ at the basement membrane of the epidermis to approximately $20 \%$ at the skin surface. Upon application of transfersomes to the skin surface, the formulation will dry, and the vesicles start to partially dehydrate, resulting in the liposome becoming flattened or curved. To maintain stability, the vesicle will permeate deeper into the stratum corneum, where water content is higher [18]. The hydration theory mechanism is supported by the reduction in flux observed when skin is occluded [86]. Occlusion prevents skin desiccation, resulting in loss of the 
hydration gradient - the proposed drive for transfersome transport.

Transfersomes have been successfully employed as topical and transdermal carriers for a number of drugs, including diclofenac [96], triamcinolone [97], dexamethasone [98], methotrexate [99], ketotifin [100,101], zidovudine [102], ethinylestradiol [103], retinol [104] and dipotassium glycyrrhizinate [105]. In vitro skin penetration of estradiol was found to be superior when transfersomes (17-fold increase) were compared to conventional rigid vesicles (9-fold increase) [86]. Applying empty vesicles in order to pre-treat the skin did not significantly influence drug flux. Furthermore, it was reported that the size of transfersomes had minimal effect on penetration enhancement. Subsequent work by the same group, investigated the shunt route as a possible pathway for these vesicles. The sandwich model was used, whereby a second stratum corneum membrane is placed on top of the epidermis. In theory, the probability of 2 shunt routes aligning between the 2 horny layers is extremely low. Hence, if the shunt pathway is the principal means of permeation, flux will drop dramatically. The authors reported that flux reduced in line with increased barrier thickness, thus discounted the shunt route as the main pathway for this vehicle [86]. Transdermal delivery of insulin (molecular weight approximately $6000 \mathrm{Da}$ ) using transfersomes has been shown to reduce blood glucose levels in mice [106,107] and humans [106]. Deformable liposomes applied in vivo have also been shown to be effective carriers for genetic material $[108,109]$ and vaccines [110-112]. A recent phase III clinical trial compared topical application of ketoprofen in Tranferosome ${ }^{\circledR}$ gel to a placebo gel and oral ketoprofen for the treatment of pain associated with knee osteoarthritis [113]. Efficacy of the transfersome formulation was shown to be superior to placebo and comparable to 100 $\mathrm{mg}$ twice daily of the oral NSAID.

\section{Ethosomes}

Conventional liposomes can contain up to $10 \%$ ethanol, and it had been thought that higher levels of alcohol would have a detrimental effect on the lipid bilayers [95]. However, Touitou et al. [114] demonstrated that liposomes could be prepared containing much higher levels of ethanol (etho- somes). Similarly to liposomes, ethosomes are composed of phospholipids, but can contain $20-45 \%$ ethanol [95]. Ethosomes are frequently prepared by first dissolving the lipids and drug in ethanol, then adding the aqueous component as a fine stream with thorough mixing [115]. High ethanol content results in ethosomes being much smaller than liposomes, negating the need for size reduction. Furthermore, ethanol enhances solubility of more lipophilic drugs [95].

The exact mode of action of ethosomes remains unclear [116]. Ethanol is a well known permeation enhancer [117], and phospholipids can potentially cause disruption of the intercellular domains of the horny layer [118]. However, when compared; ethosomal preparations were found to be much more effective permeation enhancers than hydroethanolic solutions, ethanol or an ethanololic phospholipid solution [115]. An alternative theory that has been proposed is that ethanol initially acts to disrupt the lipid organisation of the stratum corneum [119]. Subsequently, ethosomes, which are thought to be more flexible than liposomes due to their increased alcohol component, squeeze through the compromised horny layer (Fig. 6).

Using formulations containing ethosomes, studies have reported increased in vitro skin permeation of trihexphenidyl hydrochloride [116], cannabidiol [120], minoxidil [115], ketotifen [101], testosterone [115] and acyclovir [119]. A clinical study comparing a proprietary cream containing acyclovir to 5\% ethosomal acyclovir reported a significantly faster healing for the vesicular formulation [121]. Transdermal delivery of insulin using ethosomes has been demonstrated in vivo [119]. Lowering of blood glucose levels was seen in normal and diabetic rats, with a plateau effect observed for 8 hours, indicating percutaneous delivery of insulin and possible accumulation of insulin within the skin.

\section{NANOPARTICLES}

Solid lipid nanoparticles (SLN) and polymeric nanoparticles were originally developed for parenteral application. By incorporating drugs into nanoparticles, development obstacles, such as poor aqueous solubility or inadequate stability can be overcome. These systems can also be used to target specific anatomical sites, for example, the brain [122] or liver [123].
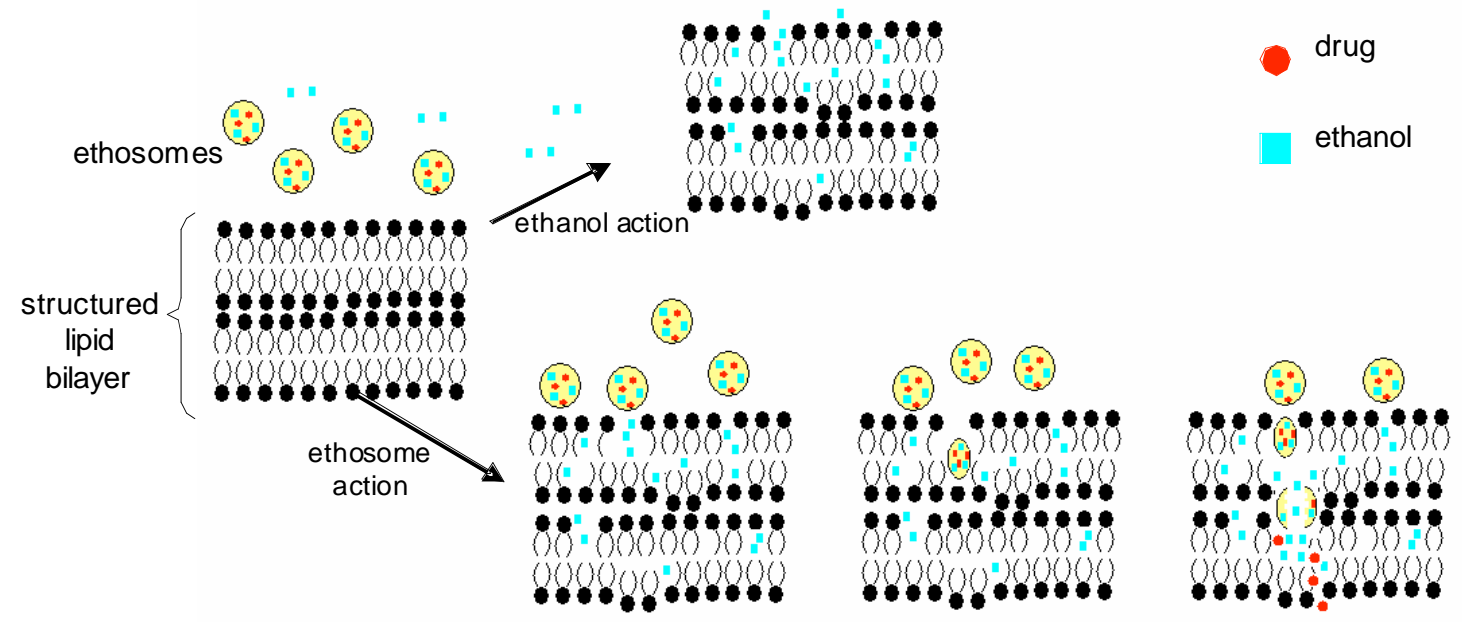

disrupted lipid bilayer

Fig. (6). Proposed mechanism of action of ethosomes (adapted from [115]). 
In terms of topical drug delivery, most work to date has involved the use of SLNs. SLNs can be produced by high pressure homogenisation or by the microemulsion technique $[124,125]$. Drug distribution within the nanoparticle is said to a function of particle composition (lipid, drug, and surfactant) and of the method of production. Drug can be homogenously dispersed throughout the matrix of the nanoparticle, or it can be localised within the core or the particle shell (Fig. 7). Drug distribution has the potential to influence drug release. SLNs with an enriched shell facilitate rapid or burst release, whereas particles with a drug loaded core lead to sustained release [125].

Maia et al. [126] compared prednicarbate penetration into freshly excised human skin from SLN dispersions and a cream. They reported a $30 \%$ increase in drug penetration into skin from the nanoparticulate system compared with the semi-solid preparation. Liu and colleagues [124] demonstrated selective skin targeting using SLN nanoparticles containing isotretinoin. In vitro penetration studies revealed that isotretinoin released from an ethanolic vehicle, could penetrate across excised rat skin. However, incorporation of the drug into SLNs, prevented transdermal delivery. Nanoparticulate formulations were shown to target isotretinoin to the upper skin layers, thus, avoiding systemic delivery. SLNs have also been successfully used to enhance topical penetration of co-enzyme Q10 [125] and retinol [127].

Several studies have investigated the use SLNs systems as sunscreens. SLNs, due to their particulate nature, can act as physical sunscreens, whereby particles reflect and scatter incoming UV radiation [128]. Alternatively, highly conjugated compounds that absorb UV radiation can be incorporated into SLNs [129]. Wissing and Muller [129] demonstrated sustained release of the molecular sunscreen, oxybenzone using a SLN system. Furthermore, SLNs were shown to reduce the rate of oxybenzone release compared to emulsion controls. Slower and more sustained release ensures that the active ingredient remains at the site of action, near the skin surface. The SLN also appears to be a promising system for skin care. An o/w cream, enriched with 4\% SLN was applied twice daily to 25 volunteers for 4 weeks [128]. The increase in skin hydration (32\%) was significantly greater compared to control (24\%). Enhanced hydration is thought to be due to a thin film of nanoparticles acting as an occlusive barrier on the skin surface [125].

Nanoparticulate drug delivery systems may be a useful way of targeting skin layers, however, in terms of transdermal drug delivery they appear to be of limited benefit.

\section{CHEMICAL PENETRATION ENHANCERS}

Substances that reversibly reduce the barrier resistance of the stratum corneum are known as chemical penetration enhancers. Properties of an ideal penetration enhancer include [19,130]:

- $\quad$ It should be non-toxic, non-irritant and non-allergenic

- It should not elicit any pharmacological activity within the body

- It should have a rapid and reproducible effect

- It should be physicochemically compatible and stable with the other components of the formulation

- $\quad$ Its action should be unidirectional. i.e. it should facilitate enhanced drug absorption into the skin, but not promote the loss of endogenous substances from the body

- When the formulation is removed from the skin, barrier integrity should recover rapidly

- $\quad$ It should be an excellent solvent for drugs

- $\quad$ It should be inexpensive

- The substance should formulate easily into semisolids, aerosols and skin adhesives

- It should be cosmetically acceptable in terms of odour, colour, taste and texture.

The most ideal penetration enhancer discovered to date is undoubtedly water. Hydration of the stratum corneum has been shown to increase the penetration of both hydrophilic and hydrophobic drugs [18, 33]. Hydration can be achieved by soaking the skin or using a formulation with high water content. More commonly, occlusion is used to prevent natural water loss from the skin, thus stratum corneum water content moves towards equilibrium with the underlying layers. Occlusion can be achieved by use of dressings, hydrophobic ointments or patch-based formulations [18]. The mechanism of action by which water increases transdermal drug penetration remains unclear. It has been suggested that small amounts of water are present in the head group regions. This water insertion loosens lipid packing, increasing mobility of the chains [131]. Larger amounts of water can exist as a separate phase in the intercellular space or can be taken up by the corneocytes [132].

A large number of other chemicals have been evaluated as potential permeation enhancers. This review aims to highlight several of the more frequently used agents.
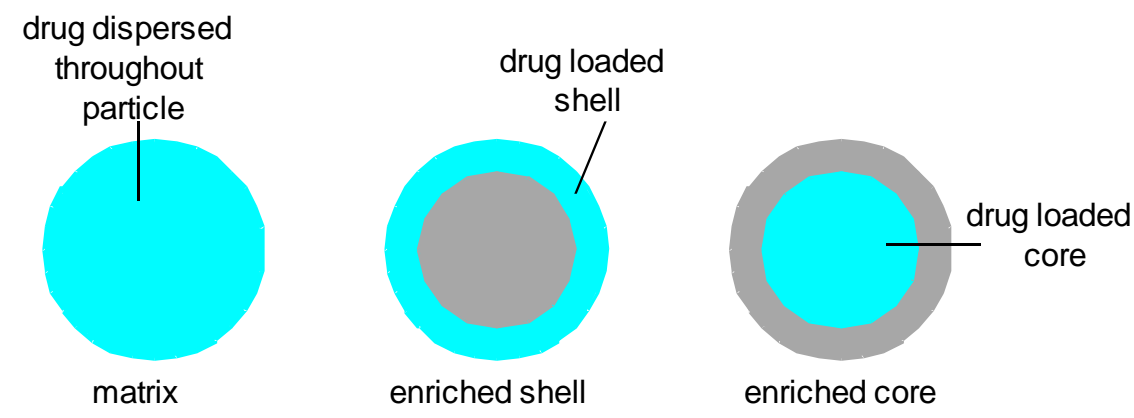

Fig. (7). Drug distribution patterns seen in nanoparticulate systems. 


\section{Alcohols}

Ethanol is one of the most commonly used permeation enhancers [133]. Estraderm ${ }^{\circledR}$, containing estradiol was the first commercial transdermal system to use ethanol as a permeation enhancer [134]. A number of mechanisms have been proposed for permeation enhancing action of ethanol. As a solvent, ethanol can be included in the formulation to enhance the solubility of the drug. This is particularly important for poorly soluble permeants, as they are prone to depletion in the donor vehicle [18]. Ethanol is a relatively volatile solvent and will rapidly evaporate at skin temperature. Ethanol loss from a formulation may lead to the drug becoming supersaturated, which will influence drug flux across the membrane. In addition, ethanol is thought to alter the solubility properties of the stratum corneum, facilitating improved drug partitioning [38]. A recent study by Heard et al. [135] reported a close correlation between the permeation rates of ethanol and mefenamic acid across excised porcine ear skin. The authors proposed a 'pull' or 'drag' effect, whereby the permeation of the enhancer facilitates simultaneous drug penetration via a solvation or complexation interaction. Furthermore, it has been suggested that alcohols may extract lipids in the stratum corneum. Chloroform and methanol mixture is said to be the most effective extractant, removing all except the lipids covalently bonded to the corneocyte envelope. Ethanol is a milder solvent, extracting only some of the skin lipids [136].

Ethanol has been employed in vitro to enhance transdermal delivery of levonorgesterol, hydrocortisone and 5fluorouracil across rodent skin [117], and estradiol across human skin in vivo [137]. Megrab and collaborators [138] noted that the enhancement effect of ethanol was concentration dependent. Estradiol flux across human epidermal membrane increased up to $60 \%$ ethanol, with higher concentrations causing reduced drug penetration. The authors investigated the effect of ethanol on skin water content and concluded that formulations containing high levels of alcohol were capable of dehydrating the skin, which may explain the concentration dependant action of ethanol.

\section{Azone}

Azone (1-dodecylazacycloheptan-2-one or laurocapram) has been specifically designed as a chemical permeation enhancer [18], and was first patented in 1976 [20]. At room temperature, Azone is a clear liquid, with a molecular weight of $281 \mathrm{Da}$. It is strongly lipophilic $\left(\log \mathrm{P}_{\mathrm{ow}} 6.2\right)$, and is compatible with most organic solvents. Its structure is comprised of a large polar head group and $\mathrm{C}_{12}$ side chain (Fig. 8). An important advantage of Azone is its ability to enhance penetration at low concentrations [20]; with optimum enhancement frequently observed at loadings of $1-3 \%[18,133]$.



Fig. (8). Chemical structure of Azone.

Barry [131] used thermal analysis of human stratum corneum to elucidate the mechanism of action for several permeation enhancers. No interaction was observed between Azone and proteins, indicating that the agent does not enter corneocytes in significant amounts. Differential scanning calorimetry
(DSC) data suggested that lipophilic Azone partitions into lipid bilayers of the stratum corneum, resulting in distortion of lipid packing geometry.

Azone is an effective permeation enhancer for both hydrophilic and lipophilic permeants [139-141]. For example, Azone was shown to enhance 5-fluorouracil penetration by 100-fold across hairless rat skin [142]. Triamcinolone acetonide, a more lipophilic drug, displayed a 2-5-fold increase in drug flux in vivo when Azone was employed [143].

\section{Dimethylsuphoxide}

Sulphoxides are compounds containing a sulfinyl group $(\mathrm{S}=\mathrm{O})$ attached to 2 carbon atoms. The most commonly used permeation enhancing sulphoxide is dimethylsulpoxide (DMSO, Fig. 9). It is miscible with both water and organic solvents, enabling it to be easily formulated into pharmaceutical preparations [19]. Owing to its aqueous solubility (log $\mathrm{P}_{\mathrm{ow}}-1.35$ ), DMSO is thought to act primarily at the polar head region of the lipid bilayers. At high concentrations $(>60 \%)$, DMSO may also interact with stratum corneum lipids [144]. Furthermore, DMSO presence in the horny layer could aid partitioning of some drugs [131].



Fig. (9). Chemical structure of DMSO.

DMSO has a long history of being used as a permeation enhancer, and several reviews have highlighted its ability to enhance the penetration of both hydrophilic and hydrophobic drugs $[20,145,146]$. Recent studies have shown significant improvement in skin penetration in vitro of azathioprine [147], cyclosporin A [148] and prazosin [149]. However, Jantharaprapap and Stagni [150] reported no improvement in meloxicam penetration across excised human skin, using vehicles containing up to $10 \%$ DMSO.

DMSO efficacy is strongly concentration-dependant, with co-solvents generally requiring greater than $60 \%$ DMSO. At such high levels, topical application of DMSO is associated with a number of side effects, such as erythema, scaling, contact urticaria, burning and systemic symptoms, for example, bad breath $[18,151]$. Due to these difficulties, structurally related compounds have been developed as more acceptable permeation accelerants, for example dimethylacetamide [152], dimethylformamide [153] and decylmethylsulphoxide [154].

\section{Fatty Acids}

Fatty acids are carboxylic acids, often with long unbranched aliphatic tails. Examples of fatty acids employed as penetration enhancers include lauric acid, linoleic acid and oleic acid (Fig. 10). Penetration enhancement has been shown to be influenced by the number, position and type (cis/trans) of double bonds [19]. Generally, unsaturated fatty acids possessing the cis configuration are more effective enhancers of drug penetration [133]. The cis double bonds introduce a 'kink' into the alkyl tail. The bent or 'kinked' tail to thought to cause greater disruption to lipid bilayers than the straight trans configuration fatty acids, which differ little from saturated fatty acids [146]. Furthermore, alkyl chain length is also of significance, with $\mathrm{C} 10$ and $\mathrm{C} 12$ carbon chain lengths providing greatest permeation enhancement [155]. 




Fig. (10). Chemical structure of oleic acid.

Oleic acid is a 'kinked' fatty acid with a double bond in the cis configuration, located halfway along the $\mathrm{C}_{18}$ chain. Thermal analysis of human stratum corneum indicated that the site of action for oleic acid is principally the stratum corneum lipids [131]. The bent structure of the enhancer disrupts intercellular lipid packing, facilitating enhanced drug mobility. Disruption of lipid bilayers was also proposed by Jiang and Zhou [156] who used electron microscopy to examine structural alterations induced by oleic acid.

In vitro studies indicate that fatty acids can be used to enhance topical penetration of a range of drugs, including 5aminolevulinic acid [157], naloxone [158], 5-fluorouracil [158-160], estradiol [160], methotrexate [158], melatonin [161], physostigmine [162], sumatriptan [163] and oxymorphone [164]. Nanayakkara et al. [165] reported an inverse relationship between permeant lipophilicity and enhancement effect of several fatty acids. The authors suggested that fatty acids augment the polar pathway across the skin by interacting with polar and non-polar regions of the horny layer. Jantharaprapap and Stagni [150] reported a 6-fold increase in meloxicam flux across human cadaver skin, from gels containing $1 \%$ oleic acid, compared to control. When the concentration of oleic acid was increased above $1 \%$, meloxicam penetration reduced. The authors suggested this was due to oleic acid hindering meloxicam partitioning from the vehicle to the stratum corneum. Rastogi and Singh [167] reported a 4-fold increase in insulin delivery across excised porcine epidermis using linolenic acid to pre-treat the skin. By combining the use of the enhancer with iontophoresis, the authors demonstrated a 15-fold increase in insulin flux compared to control.

\section{Pyrrolidones}

Natural moisterising factor (NMF) is a composite term for a group of substances found in the skin that are known to maintain stratum corneum hydration. One of these components is pyrrolidone carboxylic acid [168]. Although there remains some doubt as to the enhancing ability of pyrrolidone carboxylic acid, various analogues have been examined. N-methyl-2-pyrrolidone (NMP) and 2-pyrrolidone
(2P) are the most widely used of these related compounds (Fig. 11).

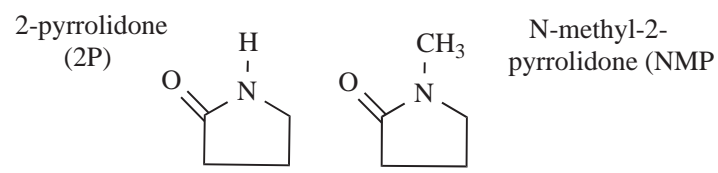

Fig. (11). Chemical structures of 2-pyrrolidone and N-methyl-2pyrrolidone.

NMP and 2P are polar solvents, and at low concentrations have been shown to primarily interact with keratinised regions of the horny layer. At higher levels they also interact with the polar head groups of the lipid bilayers. The high water solubility of the NMP and $2 \mathrm{P}$ probably inhibit their migration into lipid chains. Rather, the enhancers may displace water from the polar head groups creating a larger solvation shell (Fig. 12), which may in turn disrupt lipid packing [131].

Large increases in the transdermal penetration of several hydrophilic permeants (up to 450-fold) have been reported using NMP and 2P, whereas enhancement of lipophilic drugs is less remarkable [18,169]. Babu and Pandit [170] examined the effect of NMP and 2P on skin penetration (excised rat skin) of bupranolol from a reservoir-type patch system. NMP and $2 \mathrm{P}$ enhanced drug penetration rates 1.5 - and 3.0-fold, respectively, compared to control. Liu et al. [148] reported enhanced topical deposition of cyclosporin A, into excised rat skin pre-treated with NMP, compared to control. However, the authors reported no significant increase in transdermal delivery of the drug. In a recent study, hydrogels containing NMP exhibited a significantly greater flux of griseofulvin across mouse skin in vitro than control [171]. Pyrrolidones are associated with local adverse reactions, including irritant dermatitis [172] and erythema [18], which precludes them from clinical use.

\section{Surfactants}

Surfactants are amphiphilic molecules, usually composed of a lipophilic alkyl chain (tail) connected to a hydrophilic head. They are classified by presence of charged groups on the head moiety. A non-ionic surfactant carries no charge, whereas negatively and positively charged head groups are associated with anionic and cationic surfactants respectively. If a surfactant contains a head with two oppositely charged groups, it is termed zwitterionic.

Sodium lauryl sulphate (SLS) is an anionic surfactant, and acts on the horny layer in a concentration-dependant
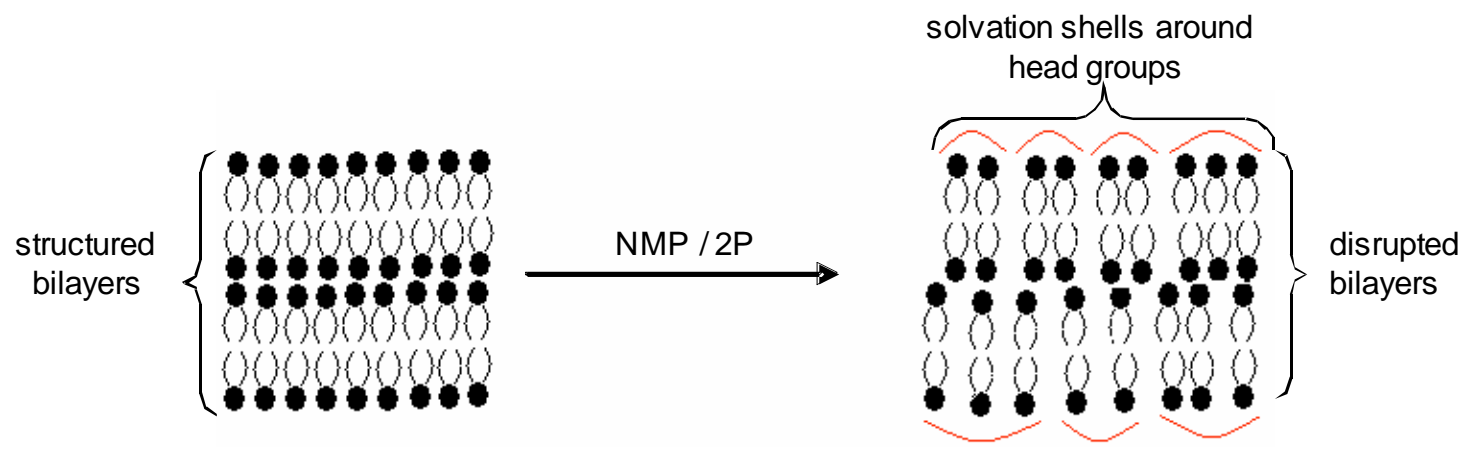

Fig. (12). Possible mechanism of action for Pyrrolidones (adapted from [131]). 
manner. At $1 \%$, SLS was shown to markedly disrupt both lipid and protein components of the stratum corneum in an at least partially reversible manner [131]. Barry proposed that the surfactant imbibes water, causing expansion of the intercellular spaces, with subsequent disruption of the lipid structures [13]. Baby et al. [173] examined the effect of surfactant charge on stratum corneum water content using DSC. The authors found that anionic surfactants were able to cause an increase in water content within the stratum corneum.

The majority of surfactants used in penetration enhancement studies have been anionic or non-ionic. Rat skin, pretreated with SLS $(0.5 \% \mathrm{w} / \mathrm{w})$ was found to reduce the lag time for cyclosporin A penetration into deeper skin layers, and enhance the amount of cyclosporin A retained in the skin, compared to control [148]. Furthermore, the surfactant was shown to enhance the amount of drug permeated across rat skin 2-fold after 12 hours. Nokhodchi and coworkers [174] examined the influence of non-ionic (Tween 80), cationic (benzalkonium chloride and cetyltrimethylammnonium bromide (CTAB)), and anionic (SLS) surfactants on the penetration of lorazepam across excised rat skin. The greatest enhancement effect was observed at $1 \%$ for Tween 80 (3.75-fold over control) and benzalkonium chloride (7.66fold over control). Reduction in permeation rate above $1 \%$ was attributed to the formation of surfactant micelles. Incorporation of lorazepam into these micelles was suggested to reduce the thermodynamic activity of the drug and decrease drug flux. CTAB and SLS exhibited maximum permeation enhancing effect at $5 \%$ surfactant concentration. However, the authors proposed that this increase was due to the surfactants damaging the skin. Surfactants have also been used to augment physical penetration enhancement strategies, such as ultrasound [175] and iontophoresis [176].

\section{Terpenes}

Terpenes are non-aromatic compounds found in essential oils. They are lipophilic substances with relatively high log $\mathrm{P}_{\mathrm{ow}}$ values [133]. They are widely used as flavouring and fragrance agents. However, recently they have been examined as potential candidates for permeation enhancement. The FDA have classified a number of terpenes as GRAS (generally recognised as safe) and Kang et al. [177] demonstrated that the enhancing effects of terpenes are reversible. Examples of terpenes include carvone, cineole, menthone and eucarvone. The most common terpene employed as a penetration enhancer is menthol (Fig. 13).

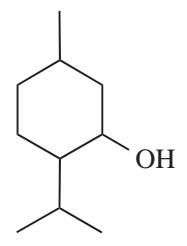

Fig. (13). Chemical structure of Menthol.

The mode of action of terpenes has been attributed to their ability to disrupt intercellular packing of stratum corneum lipids [178-180]. However, Heard et al. [135] proposed a 'pull' mechanism was responsible for enhanced penetration of mefenamic acid, mediated by the terpene, 1,8cineole. The authors examined the penetration of both mefenamic acid and 1,8-cineole across porcine ear skin. A li- near correlation was reported when the steady-state flux of mefenamic acid was plotted against the terpene. It was proposed that permeation of the terpene of through the skin, 'pulled' or 'dragged' the solute by a solvation or complexation interaction.

Terpenes have been used in vitro in enhance skin penetration of caffeine [181], cyclosporin A [148], diclofenac [182], hydrocortisone [181], anipyrine [183], indomethacin [183], 5-fluorouracil [184], meloxicam [166], midazolam [185], and sumatriptan [186]. Amnuaikit et al. [187] prepared polymeric films containing propranolol, and the terpene, cineole. Cineole $(10 \% \mathrm{w} / \mathrm{w})$ was shown to enhance propranolol flux across excised rat skin by almost 2-fold compared to control. Monti and colleagues [188] investigated the permeation enhancing effect of terpene-containing essential oils on the penetration of estradiol across excised hairless mouse skin. Niaouli oil, a complex mixture of 4 terpenes was found to enhance estradiol flux by almost 60 -fold compared to control. Furthermore, the authors demonstrated a significantly improved enhancement effect for the complex oily mixture, compared to the components applied neat or in admixture. Recently Fang et al. [189] evaluated several terpenes as enhancers for transdermal delivery of tea catechins and theophylline in vitro and in vivo. Physicochemical characteristics of the terpenes were found to strongly influence drug penetration, with agents containing oxygen having increased enhancing activity, and bicyclic terpenes having reduced enhancing activity. Rastogi and Singh [167] reported that iontophoretic delivery of insulin was significantly enhanced through limonene pre-treated epidermis compared to control. The authors proposed that such a system would be able to delivery 50 IU of insulin within $3 \mathrm{~h}$.

\section{Other Chemical Permeation Enhancers}

No compilation of permeation enhancers is likely to be exhaustive. However, other classes of compound used as chemical permeation enhancers include aminoacetates [190], phospholipids [191], oxazolidinones [20], esters [192], fatty alcohols [155], amides [155], amines [158], urea and derivatives [193], esters [194] and iminosulfuranes [195,196].

\section{Penetration Retarders}

Penetration retarders or reducers, have the opposite effect to permeation enhancers. In terms of drug delivery, they can be used to restrict drug localisation to the upper layers of the skin, reducing dermal and transdermal penetration [18]. Such agents may have application in formulations that contain sunscreens, pesticides or drugs with specific local skin targeting. The mechanism of action of permeation retardants is not fully understood. They may act as an antisolvent, preventing drug partitioning or add more lipid-like molecules to the lipid bilayers to enhance stratum corneum rigidity [18]. Hadgraft et al. [197] examined the influence of Azone and 5 of its analogues on the skin penetration of metronidazole and diethyl $m$-toluamide. They reported that 1 of the analogues acted as a retardant, producing an enhancement ratio of 0.2 at 40 hours compared to control. Furthermore, the compounds were tested for their ability to reduce the phase transition temperature of dipalmitoyl phoshatidylcholine multilamellar vessicles. The retarder, termed N-0915, was shown to actually increase the phase transition temperature, indicating that it was stabilising the lipid bilayers. 


\section{TAPE STRIPPING}

Wolf's skin-stripping technique [7], removes successive layers of the stratum corneum by repeated application of adhesive tape to the skin surface. Tsai et al. [198] examined the effect of tape stripping on the molecular weight cut-off of propylene glycol (PEG) penetration across mouse skin in vitro. Stripping of the stratum corneum facilitated permeation of PEGs up to 986 Da, whereas, control skin displayed a molecular cut-off of $414 \mathrm{Da}$. Tape stripping has also been shown to enhance topical penetration of both 5-aminolevulinic acid and hexyl aminolevulinate across mouse skin in vivo [199].

Although tape stripping in as inexpensive way of reducing the barrier function of the stratum corneum, it is inconvenient, shows poor reproducibility and is unlikely to be acceptable for routine use by patients.

\section{LASER ABLATION}

Laser ablation is a controlled technique which creates pores in the stratum corneum. Holes are produced by matching the energy wavelength to the main absorption peak of water $(2790 \mathrm{~nm})$ or tissue proteins $(2940 \mathrm{~nm})$. Vibrational heating causes skin components within the irradiated area to rapidly reach boiling point. The resultant vapour pressure induces a microexplosion, resulting in pores as the tissue vaporises. The surrounding skin is protected from heatrelated damage due to the rapid reduction in energy from the ablated site.

Laser ablation has been successfully used to enhance skin penetration of 5-fluorouracil [200], 5-aminolevulinic acid [201,202], hydrocortisone [203], nalbuphine [204] and indomethacin [204]. The technique has also been successfully performed with peptides and DNA [205]. Irradiation of pigskin at $2790 \mathrm{~nm}$ using an erbium: yttrium-scandium-galliumgarnet (Er:YSGG) laser, resulted in a 2.1-fold increase in interferon- $\gamma$ transport [203]. Fang et al. [206] examined the effect of molecular weight on the transdermal delivery of macromolecules using an erbium:yttium-aluminium-garnet (Er:YAG) laser $(2940 \mathrm{~nm})$. The study reports transdermal delivery of model macromolecules up to $77 \mathrm{kDa}$ across excised pig skin pre-treated using the laser.

Due to the relatively high cost of medical lasers, this type of technology may be restricted to the hospital setting for specialised procedures. In addition long-term safety concerns need to be addressed.

\section{SUCTION ABLATION}

Suction ablation utilises a vacuum to produce a small blister on the skin. Using an epidermatome, the upper surface of the blister is removed, providing a pathway of low resistance for drug penetration. This strategy has been employed to enhance transdermal delivery of the antidiuretic peptide 1deamino-8-D-arginine [207], morphine [208], and antocin [209]. This technique is a multi-step process and is unlikely to be convenient for routine use by patients or clinicians. In addition, the time taken for blister formation can be up to $2.5 \mathrm{~h}$ [22]. There has been an absence of published work since 1996.

\section{THERMAL ABLATION}

Enhanced transdermal delivery using radiofrequency (RF) thermal ablation was first described by Sintov et al.
[210]. Needle-like electrodes were inserted into the skin, while an alternating current at radiofrequency $(100 \mathrm{kHz})$ was applied to each of the electrodes. Ions within the skin attempt to follow the change in direction of the alternating current, resulting in frictional heating and subsequent cell ablation. The authors reported an increase in transepithelial water loss (TEWL) following RF treatment. Upon microscopic examination, microchannels measured approximately $70 \mu \mathrm{m}$ in depth and $30 \mu \mathrm{m}$ in diameter. Significant improvements in transdermal delivery of diclofenac and granisetron were demonstrated, both in vitro and in vivo using animal models.

Microscopic pores in the stratum corneum have been generated using an array of electrically resistant filaments [211]. The array was placed on rat skin, and briefly heated using an electrical current. The thermal energy delivered to the skin from each filament ablates the stratum corneum, culminating in an array of micropores. This strategy was used to delivery interferon alpha-2B across hairless rat skin in vivo. Furthermore, the dose administered was doubled when microporation was combined with iontophoresis.

To date, thermal ablative methods rely on a 2-step process, whereby, the skin is first treated and then the formulation applied. For a system to be convenient for regular use, the processes of stratum corneum disruption and drug delivery need to be integrated within the same device. In addition, long-term safety data is required to determine if repeated use of such devices can cause irreversible skin damage.

\section{MICROSCISSIONING}

Herndon and coworkers [212] reported a novel strategy of disrupting the skin barrier involving the use of accelerated 'sharp' particles (microscissioning). Aluminium oxide particles (10-70 $\mu \mathrm{m}$ diameter) are accelerated under a pressurised stream of nitrogen, and directed towards the skin. Tissue is scized (cut) by high velocity particles, resulting in formation of microconduits (Fig. 14). Surrounding skin is protected by a Teflon or polyimide mask. The authors report that pores were fully open and up to $200 \mu \mathrm{m}$ deep. Anaesthesia following topical application of lidocaine was significantly faster when the skin of human volunteers was pre-treated with microscissioning compared to control.

Microscissioning currently requires a skin preparation step, prior to application of the drug formulation, which will limit its appeal for routine use. Deposition of particles within the skin and potential to cause infection are safety concerns that need to be addressed before this experimental technology becomes more widely used.

\section{MICRONEEDLE FACILITATED DRUG DELIVERY}

The first report of microneedle (MN) assisted topical drug delivery was in the late 1990's, whereby puncturing the skin using micron-sized needles was shown to increase permeability of human skin to a model drug, calcein, by up to 4 orders of magnitude in vitro [213]. Subsequently, there has been intense interest in this technology with significant developments being made both in the fields of $\mathrm{MN}$ fabrication and drug delivery. 




Fig. (14). Schematic diagram of microscissioning process.

MN arrays (Fig. 15) are manufactured based on etching methods used by the microelectronics industry to create arrays of micron-sized needles [214,215]. The majority of studies to date have used silicon or metal MNs, although devices have also been made from dextrin [216,217], glass [218], maltose [219,220], and various polymers [221-224]. MNs can be made of varying length, as short as $25 \mu \mathrm{m}$ and as long as $2000 \mu \mathrm{m}$. In addition, base diameter of the needle and needle density can also be altered. These devices have been shown to penetrate across the stratum corneum and into the viable epidermis, avoiding nerve fibres and blood vessels that reside primarily in the dermal layer. The overriding benefit of using MNs is the promise of pain-free injection of both small and large molecular weight active pharmaceutical ingredients [225].

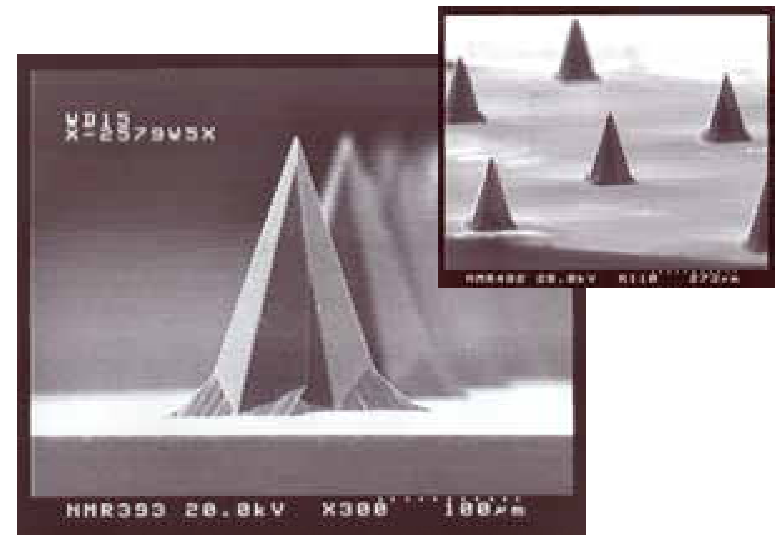

Fig. (15). Scanning electron microscope (SEM) image of solid silicon $\mathrm{MNs}$.

In terms of structure, there are essentially two types of MN: solid and hollow needles. Solid MN can be employed by inserting the needles into the skin for a defined period of time. Following removal of the device, a drug-loaded vehicle is applied to the skin surface. Microchannels produced from the application of microneedles facilitate drug transport to the viable epidermis. Alternatively, solid needles can be coated with drug, and inserted into the skin. Upon removal of the device, drug remains deposited within the membrane [226,227]. Erodable solid MNs dissolve when the device is inserted into the skin. Drug can be incorporated directly into soluble needles, or a formulation applied to the MN-treated skin. Hollow MNs are somewhat more sophisticated, in that they have a hollow bore down through the centre of the needle $[218,228,229]$. When inserted into the skin, the hollow centre effectively bypasses the stratum corneum, creating a direct channel to the lower layers of the epidermis.

MN technology has been shown to enhance transdermal delivery of a wide range of molecules, including anthrax vaccine [230], $\beta$-galactosidase [231] calcein [213,221,222, $224,232]$ bovine serum albumin [221,222,224,232] desmospressin [233]; diclofenac [228,234,235], erythropoietin [217], methyl nicotinate [236], ovalbumin [227,237] and plasmid DNA [231,238]. The most widely studied drug with regards to MN-mediated delivery is insulin, with enhanced penetration reported in vitro $[218,224,239]$ and in vivo $[216,218,224,228,229,234,235]$. A recent study by Nordquist et al. [235] described a novel delivery system which combined an array of hollow MNs with an expandable insulin containing reservoir. Electrically heating the device causes silicone within the reservoir to expand, forcing the drug through the hollow needles. Using diabetic rats, the authors reported comparable insulin delivery between the $\mathrm{MN}$ system and subcutaneous injection. Furthermore, by adjusting the silicone expansion rate, serum insulin levels could be controlled. Smart and Subramanian [240] described a novel MN-based system designed to painlessly monitor blood glucose. Under microprocessor control, a $2 \mathrm{~mm}$ MN was inserted in the skin of human volunteers. Blood was sampled via the MN (200 nanoliter), and glucose levels analysed. Glucose assay performance was shown to be comparable to an accepted commercial device, and pain perception in patients was reduced compared to a traditional lancet.

Although MN-based systems have shown promising results in animal models they have several limitations that need to be addressed. Firstly, devices are of restricted volume and surface area. Therefore, loading drug directly into needles or coating drug onto needles is only feasible for extremely potent drugs [241]. Hollow MNs have only one outlet and may become blocked by compressed dermal tissue [242]. The use of solid, non coated MNs generally requires a 2 -step process, which is undesirable [243,244]. Silicon is not an FDA-approved biomaterial and safety concerns exist in 
relation to the breaking of silicon and metal microneedles [241]. To date, no study has investigated the reversibility and consequences of long term applications of these devices or the potential to transmit infection In addition, silicon MNs are expensive to produce, requiring dedicated clean room facilities.

\section{ULTRASOUND}

Acoustic waves with frequencies between $20 \mathrm{~Hz}$ and 20 $\mathrm{KHz}$ lie within the audible range. Ultrasound describes sound waves whose frequency is beyond $20 \mathrm{KHz}$ [245]. The use of ultrasound to enhance topical or transdermal drug delivery is termed sonophoresis or phonophoresis and has been studied for over 50 years [246]. Permeation enhancement induced by ultrasound is particularly significant at low frequencies $(<100 \mathrm{kHz})$ [247]. Ultrasound can be used to pre-treat the skin, prior to drug delivery, or the formulation can be applied at the same time.

The effects of ultrasound on the skin can be described as thermal or non-thermal. Skin absorption of ultrasound can result in significant local heating which, in turn, may accelerate drug diffusion, increase drug solubility, and enhance local blood flow [245,248]. However, enhanced drug penetration across skin can not solely be explained by the heat effect [18]. The most significant effect of ultrasound is thought to be the growth and oscillation of gaseous cavities, an effect termed cavitation $[245,246]$. In the low pressure portions of an ultrasound wave, dissolved gases can form air bubbles. Subsequent waves of higher pressure can cause these bubbles to grow in size and oscillate, which is thought to induce sheer stresses on cells and tissues (stable cavitation). Transient or inertial cavitation occurs at greater acoustic pressures, where collapse of bubble results in generation of high pressure shock waves. Such shock waves are thought to disrupt the stratum corneum, thereby enhancing skin permeability [249].

Low-frequency ultrasound (frequencies below $100 \mathrm{KHz}$ ) has been used to enhance delivery of a range of low and high molecular weight drugs across the skin $[245,250]$. In vitro studies using human stratum corneum demonstrate enhanced transport (by several orders of magnitude) of the macromolecules insulin, interferon- $\gamma$, and erythropoietin using low frequency ultrasound [251]. Recently, Park and collaborators [252] used a compact, light weight low frequency transducer to enhance transdermal insulin delivery. Live adult pigs were anaesthetised, and xylazine administered to induce hyperglycaemia. The ultrasound-treated group showed a significant reduction in blood glucose, compared to control. The authors proposed that the device was capable of safely reducing blood glucose to a normal range.

In vitro and in vivo studies have demonstrated the efficacy of sonophoresis, with some studies reporting up to 1000 -fold better penetration compared to simple topical application. However, challenges remain in terms of gaining a full understanding of how the technology operates and to fully evaluate its safety profile [246]. Singer et al. [253] demonstrated that low-intensity ultrasound induced only minor skin reactions in dogs, but high-intensity ultrasound was capable of causing second-degree burns.

\section{IONTOPHORESIS}

Iontophoresis is a century old technique whereby an electrical potential gradient is used to drive solute molecules across the skin. An electrophoretic device consists of a power source, terminating with a positive electrode (anode), and a negative electrode (cathode) (Fig. 16). Drug transport across the skin is facilitated by 2 primary mechanisms, electrorepulsion and electroosmosis. Using electrorepulsion, whereby, like charges repel each other, delivery of a positively charged drug $\left(\mathrm{D}^{+}\right)$can be achieved by dissolving the drug in a suitable vehicle in contact with an electrode of similar polarity (anode). Application of a small direct current (approximately $0.5 \mathrm{~mA} \mathrm{~cm}$ ), causes the drug to be repelled from the anode, and it is attracted towards to the oppositely charged electrode (cathode) [254]. This process is termed anodal iontophoresis. Conversely, cathodal iontophoresis occurs when anions $\left(\mathrm{D}^{-}\right)$are repelled from the cathode, towards to the anode. Importantly, iontophoresis is not only reserved for charged drugs. Delivery of small neutral molecules may also be enhanced through electroosmosis. At $\mathrm{pH}$ values above 4 , the skin is negatively charged, due to ionisation of carboxylic acid groups within the membrane. Positively charged ions, such as $\mathrm{Na}^{+}$, are more easily transported, as they attempt to neutralise the charge in the skin, hence there is a flow of $\mathrm{Na}^{+}$to the cathode [254]. Owing to a net build up of $\mathrm{NaCl}$ at the cathodal compartment, osmotic flow of water is induced from the anode to the cathode. It is this net flow of water that facilitates transfer of neutral molecules across the skin.

The transappendgeal route is thought to offer the path of least electrical resistance across the skin and is suggested to be the principal pathway taken by a permeant during electophoresis [255]. Many factors influence electorphoresis, including $\mathrm{pH}$ of the donor solution, electrode type, buffer concentration, current strength and current type. These parameters have been reviewed extensively elsewhere [18,255-258].

Iontophoresis has been used to enhance transdermal delivery of a wide range of relatively small molecules, including apomorphine [259], rotigotine [260], 5-fluorouracil [261], 5-aminolevulinic acid [262], fentanyl [263], piroxicam [264], non steroidal anti-inflammatory drugs (NSAIDs) $[265,266]$ and buspirone hydrochloride [267]. A recent study by Patel et al. [268] investigated delivery of sumatriptan from an iontophoretic patch system. In vivo pharmacokinetic studies, using the pig model, indicated that the iontophoretic patch achieved similar blood levels as those seen following oral, nasal and rectal delivery. However, the maximum concentration $\left(\mathrm{C}_{\max }\right)$ and time to $\mathrm{C}_{\max }\left(\mathrm{T}_{\max }\right)$ were significantly lower and longer respectively, compared to subcutaneous injection. Vyteris, (Fair Lawn, NJ) has received approval for an iontophotetic patch containing lidocaine and adrenaline $\left(\right.$ LidoSite $\left.^{\mathrm{TM}}\right)[76,255]$. Adrenaline is a vasoconstrictor and reduces lidocaine clearance from the site. Phase III clinical studies demonstrated that both children and adults, experienced significantly less pain associated with venipuncture or IV cannulation when treated with the Vyteris system compared with the placebo system [256].

The most widely studied macromolecule, in terms of iontophoretic delivery is insulin. Monomeric human insulin has 


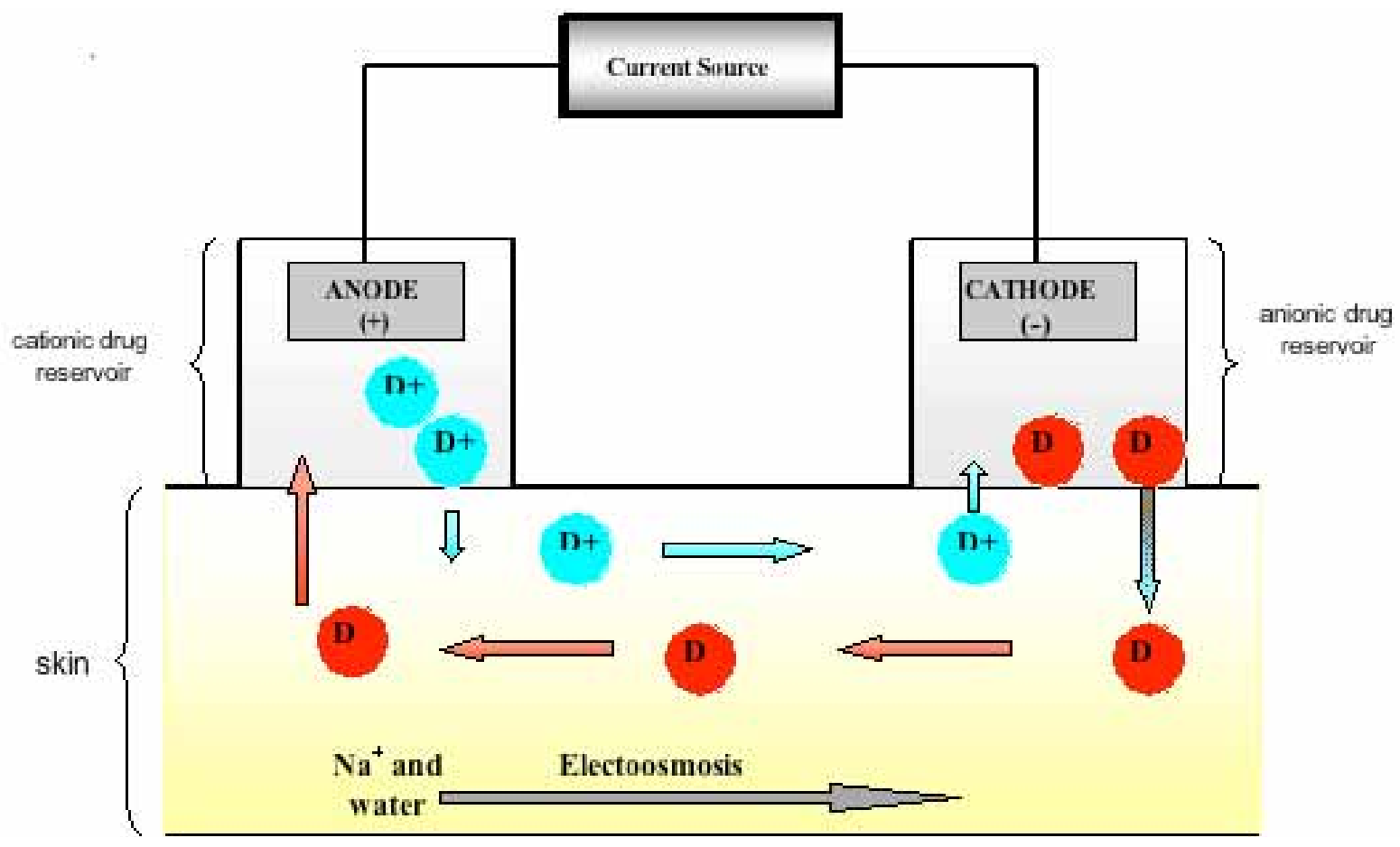

Fig. (16). Schematic representation of iontophoresis.

a molecular weight of approximately $6000 \mathrm{Da}$ [256]. In vivo studies have demonstrated increased insulin delivery in animals, using iontophoresis [269-271]. However, achieving even the basal insulin rate $\left(0.5-1.0 \mathrm{IU} \mathrm{h}^{-1}\right)$ in humans is likely to be extremely challenging [256]. Other peptides that have been successfully delivered across the skin via iontophoresis include salmon calcitonin [272], human parathyroid hormone [273], luteinising hormone-releasing hormone (LHRH) [274], vasopressin [275] and somatostatin analogues [276,277]. Iontophoresis has traditionally been used to enhance transdermal drug delivery. However, by using 'reverse iontophoresis'; substances can be extracted from the skin and analysed. This technique offers a non-invasive means of monitoring glucose and drug levels in the blood [278].

The main advantage of iontophoresis over other transdermal enhancement strategies is its ease of control. Electrical current is responsible for the increased delivery [134]. Therefore, by manipulating current density, and duration, the dose may be tailored to an individual patient's needs. An example of this concept is the fentanyl $\mathrm{HCl}$ iontophoretic transdermal system (IONSYS ${ }^{\mathrm{TM}}$ ), which has been approved in the USA and Europe for the management of acute, moderate-to-severe postoperative pain. The system allows patients to selfadminister fentanyl according to their personal requirements for pain relief (maximum 6 doses per hour) [263,279]. The patch has been shown to provide post-surgical pain control equivalent to a standard IV morphine regimen, delivered by a patient controlled analgesia (PCA) pump [280].

Safety concerns exist over the biophysical effects of iontophoresis, such as the possibility of irreversible skin damage [254]. Recent advances in the microelectronics industry have facilitated miniaturisation of iontophoretic systems. This has resulted in the development of devices which are much more convenient for the patient and have the potential to allow home use.

\section{ELECTROPORATION}

In contrast to iontophoresis, which uses small voltages $(<10 \mathrm{~V})$, electroporation employs relatively high voltage pulses $(10-1000 \mathrm{~V})$ for brief periods of time ( $<$ a few hundred milliseconds). When applied to stratum corneum, pulses are thought to induce formation of aqueous pores in the lipid bilayers. The aqueous pores may facilitate drug transport by passive diffusion, electroosmosis or iontophoresis during the pulse $[18,76]$. Furthermore, transdermal delivery of charged molecules may be further enhanced by iontophoretic transport through the transfollicular pathway during pulsation [281].

Electroporation has been used to deliver a number of small molecules, including tetracaine [282], lidocaine [283], nalbuphine [281], and cyclosporin [284]. Conjeevaram et al. [285] reported no measurable permeation of fentanyl through human epidermis under passive conditions. However, iontophoresis gave a flux of approximately $80 \mu \mathrm{g} \mathrm{cm}^{-2} \mathrm{hr}^{-1}$, with a 4-fold higher flux observed using electroporation. Larger molecules studied include heparin [286], parathyroid hormone [287] and DNA vaccines [141,288]. Medi and Singh [287] examined electrically facilitated transdermal delivery of human parathyroid hormone (PTH) using dermatomed porcine skin. Iontophoresis significantly enhanced the flux of PTH compared to passive delivery. Electroporation pulses of 100,200 and $300 \mathrm{~V}$ significantly increased PTH flux in comparison to passive as well as iontophoretic flux. Furthermore, the authors demonstrated that by following electroporation pulses with iontophoresis, flux was further increased by several fold. Significant disruption of the stratum corneum was reported using light microscopy. 
Electroporation has the potential to enhance transdermal delivery of macromolecules. However, more clinical studies are required to assess long-term safety of this technique and to gain a greater understanding of its mechanism of action [76]. Miniaturisation of such devices is essential to facilitate routine use by patients.

\section{JET INJECTION}

The conventional method of injectable drug delivery uses a needle and syringe. However, needle based methods have significant limitations, such as needle phobia and accidental needle stick injury [289,290]. An alternative method of injection is to deliver the drug as a high pressure jet (> 100 $\mathrm{m} / \mathrm{s}$ ), with sufficient intensity to pierce the skin [291]. This is referred to as needle-free or jet injection (Fig. 17). Devices can be powered by compressed air or by means of a compression spring [76]. There are essentially 2 types of jet injectors, liquid jet injector and powder jet injectors.

Liquid jet injectors have been shown to successfully deliver insulin [292], lidocaine [293,294] vaccines [290], human growth hormone [295], midazolam [296], bleomycin [297], interferon [298] and erythropoietin [299]. Needle-free liquid jet injectors have been associated with frequent bruising and pain, which offsets their advantages over the conventional needle and syringe approach [290]. Recent work by Arora et al. [300] demonstrated needle-free transdermal delivery of macromolecules using nanolitre-volume pulsed microjets. By using repeated injections of small injection volumes, 10-15 nanolitres, the authors proposed that pain and bruising would be minimised. In vitro studies using excised human epidermis demonstrated that on average, 48 pulses were required before the vehicle penetrated the membrane. After this lag-time (48 seconds), drug solution could be delivered at a rate of $1 \mu 1 \mathrm{~min}^{-1}$. In the same study, micro- jet delivered insulin was shown to rapidly reduce blood glucose levels in rats. Furthermore, adverse effects, such as bleeding and erythema were significantly reduced with the microjet compared to a conventional liquid jet injector.

Transdermal powdered delivery is where the therapeutic compound is formulated as a fine powder $(20-100 \mu \mathrm{m}$ diameter) and is accelerated in a supersonic flow of helium gas to penetrate the skin [301]. The PMED $^{\circledR}$ (Chiron Corporation) device, formerly known as PowderJect ${ }^{\circledR}$ [302] has been reported to successfully deliver vaccines [303,304], lidocaine [305] and testosterone [306]. Dry powder formulations are generally more stable than solutions and may negate the need for the 'cold chain' to be maintained when using vaccines, for example. This would be particularly advantageous for large-scale immunisation in developing countries with hot climates.

It is claimed that needle-free injection has several potential benefits. The fear of needles (belonephobia) and piercing (diatrypophobia) can be avoided [307]. In addition, several studies have shown that by adjusting injection parameters (e.g., injection volume) specific skin strata can be targeted. Furthermore, the use of jet injectors should avoid needle stick injuries. However, a number of limitations of needlefree injectors have been highlighted. Dosing accuracy and location of delivery may vary due to skin variability (thickness and hydration) between patients. Drugs are exposed to high shear stresses during injection, which may affect the structural integrity of proteins, vaccines and DNA. The longterm effect of bombarding the skin with high speed particles or liquids is not known; and in addition, jet injection has been associated with variable adverse reactions [307,308], and may be no less painful than conventional needle and syringe [290,309].

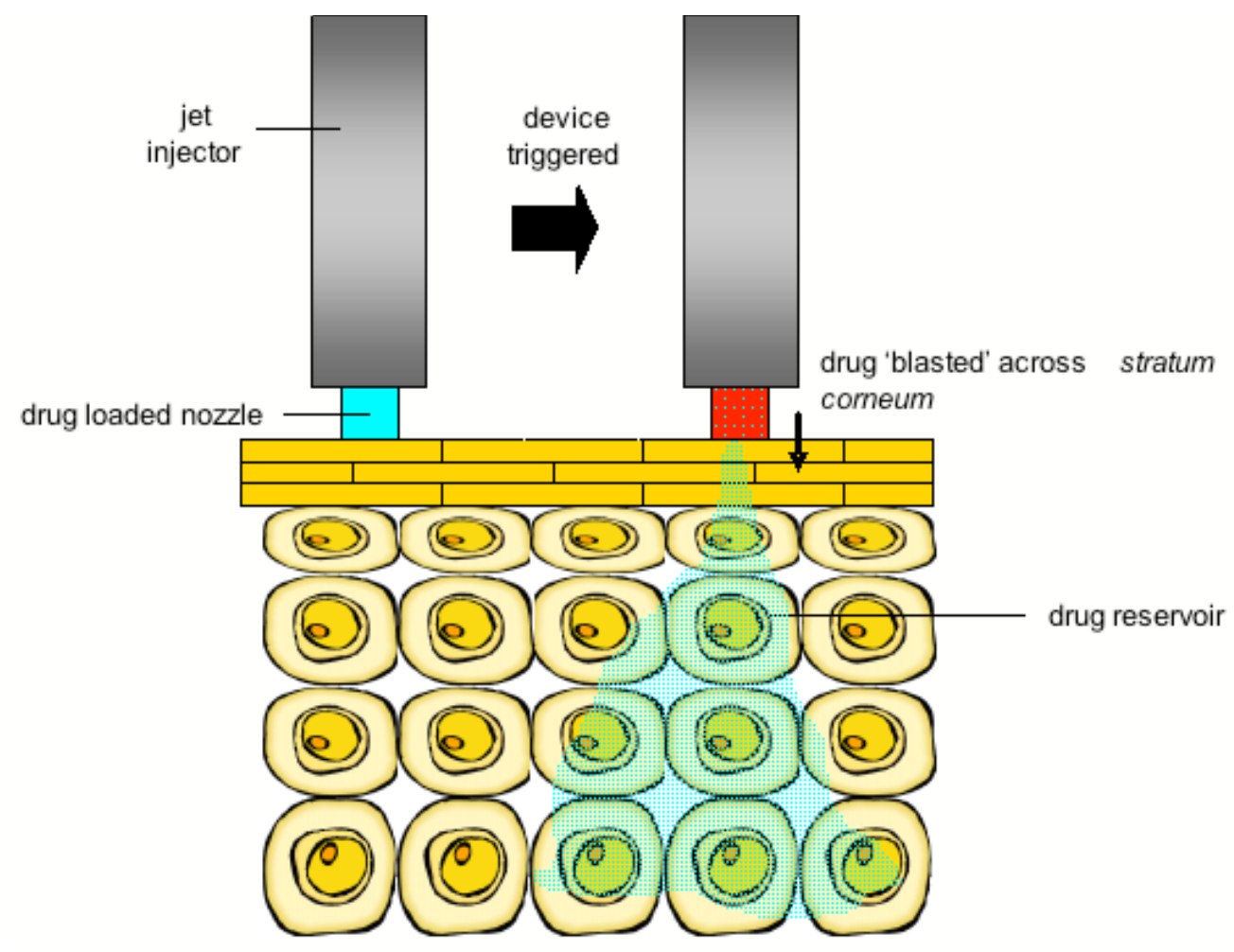

Fig. (17). Representation of the jet injection process. 


\section{OTHER PHYSICAL METHODS AND COMBINATION STRATEGIES}

In addition to the techniques described above, the literature contains reports of several other innovative strategies for enhancing transdermal drug delivery. A pulse from a high powered laser can be used to create stress or compression waves. Termed photomechanical waves (PW), these pressure pulses can be directed onto the skin to increase permeability. Lee et al. [310] demonstrated transdermal delivery of insulin in a diabetic rat model using a single laser pulse, with blood glucose levels being reduced by approximately $80 \%$. Controlled heat-assisted drug delivery (CHADD) is a disposable, self adhesive heating unit consisting of a heat-generating chemical component, sandwiched between a perforated cover film and a pressure-sensitive adhesive layer. Exposure of the powder to oxygen, results in an exothermic reaction; which is turns raises skin temperature in a controlled manner. Placing the CHADD patch over an S-Caine ${ }^{\circledR}$ patch (1:1 eutectic mixture of tetracaine and lidocaine) achieved significantly superior anaesthesia compared to placebo in a randomised double blind trial [311]. Further work by the same group, examined the influence of the CHADD system on transdermal delivery of testosterone in healthy male volunteers [312]. Placing the CHADD patch on top of a testosterone patch significantly increased the maximum serum drug concentration and reduced the time to peak testosterone concentration, compared to the androgen patch alone. Magnetophoresis is where diamagnetic substances are repelled across the skin by a magnetic field. Murthy [313] reported enhanced flux of benzoic acid, across excised rat skin using this technique. Microdialysis devices can be used to measure drug uptake into skin. A thin $(02-0.5$ $\mathrm{mm}$ diameter) semi-permeable fibre is inserted into the dermis underlying the area where the formulation is applied. Physiological solution (perfusate) is passed through the fibre, facilitating passive diffusion of substances from the dermis into the perfusate, which is subsequently assayed. Based on this technology, a self-adhesive portable microinfuser device was used do deliver therapeutic levels of morphine and heparin in healthy male volunteers [314].

The enhancement approaches described above can be used alone or in conjunction with 1 or more other techniques. For example, combined strategies that have been used to improve iontophoretic drug delivery include chemical enhancement, electroporation, ultrasound and use of microneedles $[167,257,315]$. The combination of techniques selected will influence synergism. For example, 2 strategies that both enhance transdermal delivery by creating pores may not act synergistically [18]. A better approach may be to combine a microporation technique with a system designed to enhance the driving force for drug permeation.

\section{CONCLUSION}

To date the vast majority of topical and transdermal drug formulations are based on the passive diffusion of a low molecular weight, lipophilic drugs across the skin. However, for very hydrophilic drugs or permeants with a molecular weight above 500 Daltons, skin penetration is generally poor. Over the past few decades there has been a concerted effort to develop novel and practical methods for enhancing topical and transdermal drug delivery. Many of the strategies described in this article have been shown to enhance the penetration of low molecular weight drugs and several of which have been successfully employed in commercial systems. Transdermal delivery of macromolecules, such as insulin has generally been less successful. Recently strategies, such as microneedle arrays, electroporation and iontophoresis have been shown to enhance macromolecule delivery across the skin. However, more work is needed to establish in vivo efficacy, long-term safety data and cost-effectiveness of such methods.

\section{REFERENCES}

[1] Florence AT, Salole EG, editors. Topics in Pharmacy. Routes of Drug Administration. London: Wright; 1990.

[2] Scheuplein RJ, Blank IH. Permeability of the skin. Physiol Rev 1971; 51: 702-47.

[3] Surber C, Smith EW. The mystical effects of dermatological vehicles. Dermatology 2005; 210: 157-68.

[4] Schwenkenbecker A. Das Absorption vermögen der Haut. Arch Anat Physiol 1904; 121-65.

[5] Smith HW, Clawes HA, Marshall EK. The mechanism of absorption by the skin. J Pharmacol 1919; 13: 1-30.

[6] Blank IH. Further observations on factors which influence the water content of the stratum corneum. J Invest Dermatol 1953; 21: 259-69.

[7] Wolf J. Die Innere Strucktur der Zellen des Stratum Desquamans der Menschlichen Epidermis. Anat Forsch 1939; 46: 170-202.

[8] Scheuplein RJ. Mechanism of percutaneous absorption. II. Transient diffusion and the relative importance of various routes of skin penetration. J Invest Dermatol 1967; 48: 79-88.

[9] Scheuplein RJ, Blank IH, Brauner GJ, MacFarlane DJ. Percutaneous absorption of steroids. J Invest Dermatol 1969; 52: 63-70.

[10] El-Kattan A, Asbill CS, Haidar S. Transdermal testing: practical aspects and methods. Pharm Sci Technol Today 2000; 3: 426-30.

[11] Thomas BJ, Finnin BC. The transdermal revolution. Drug Discov Today 2004; 9: 697-703.

[12] Benson HAE. Transdermal drug delivery: Penetration enhancement techniques. Curr Drug Del 2005; 2: 23-33.

[13] British National Formulary no. 53. London: RPS Publishing; 2007.

[14] Henzl MR. The promise of transdermal drug delivery - not only for reproductive steroids. [cited 2007 June 18 ]. Available from: http://www.touchbriefings.com/pdf/790/14-henzl.pdf.

[15] Wiechers JW. The barrier function of the skin in relation to percutaneous absorption of drugs. Pharm Weekbl Sci1989; 11: 185-98.

[16] Michaels AS, Chandrasekaran SK, Shaw JW. Drug permeation through human skin: theory and in vitro experimental measurement. AlChE 1975; 21: 985-96.

[17] Menon GK. New insights into skin structure: scratching the surface. Adv Drug Deliv Rev 2002; 54: S3-17.

[18] Williams AC. Transdermal and topical drug delivery. London: Pharmaceutical Press; 2003.

[19] Hadgraft J, Guy R, editors. Transdermal Drug Delivery. Developmental Issues and Research Initiatives. New York: Marcel Dekker; 1989.

[20] Asbill CS, El-Kattan AF, Michniak B. Enhancement of transdermal drug delivery: chemical and physical approaches. Crit Rev Ther Drug Carrier Syst 2000; 17: 621-58.

[21] Bouwstra JA, Gooris GS, van der Spek JA, Bras W. Structural investigations of human stratum corneum by small-angle $\mathrm{X}$-ray scattering. J Invest Dermatol 1991; 97: 1005-12.

[22] Brown MB, Martin GP, Jones SA, Akomeah FK. Dermal and transdermal drug delivery systems: current and future prospects. Drug Deliv 2006; 13: 175-87.

[23] Scheindlin S. Transdermal Drug Delivery: Past, Present, Future. Mol Interv 2004; 4: 308-12.

[24] Berlin CM, McCarver-May DG, Notterman DA, Ward RM, Weismann DN, Wilson GS, et al. Alternative routes of drug administration--advantages and disadvantages (subject review). American Academy of Pediatrics. Committee on Drugs Pediatrics 1997; 100: 143-52.

[25] Paparella S. Transdermal patches: an unseen risk for harm. J Emerg Nurs 2005; 31: 278-81.

[26] Scf-online [homepage on the Internet]. Daniels R. [cited 2007 June 15]. Available from: http://www.scf-online.com/english/37_e/skinpenetration37_e.htm. 
[27] Dokka S, Cooper SR, Kelly S, Hardee GE, Karras JG. Dermal delivery of topically applied oligonucleotides via follicular transport in mouse skin. J Invest Dermatol 2005; 124: 971-5.

[28] Wertz PW, Swartzendruber DC, Abraham W, Madison KC, Downing DT. Essential fatty acids and epidermal integrity. Arch Dermatol 1987; 123: 1381-4.

[29] Potts RO, Francoeur ML. Lipid biophysics of water loss through the skin. Proc Natl Acad Sci USA 1990; 87: 3871-3.

[30] Hadgraft J, Pugh WJ. The selection and design of topical and transdermal agents: a review. J Investig Dermatol Symp Proc 1998; 3: 131-5.

[31] Higuchi T. Physical chemical analysis of percutaneous absorption process from creams and ointments. J Soc Cosmet Chem 1960; 11: 85-97.

[32] Moser K, Kriwet K, Naik A, Kalia YN, Guy RH. Passive skin penetration enhancement and its quantification in vitro. Eur J Pharm Biopharm 2001; 52:103-12.

[33] Bronaugh RL, Maibach HI, editors. Percutaneous Absorption. 2nd ed. New York: Marcel Dekker; 1989.

[34] Poulsen BJ, Young E, Coquilla V, Katz M. Effect of topical vehicle composition on the in vitro release of fluocinolone acetonide and its acetate ester. Int Pharm Sci 1968; 57: 928-33.

[35] Kondo S, Sugimoto I. Enhancement of transdermal delivery by superfluous thermodynamic potential. I. Thermodynamic analysis of nifedipine transport across the lipoidal barrier. J Pharmacobiodyn 1987; 10: 587-94.

[36] Iervolino M, Cappello B, Raghavan SL, Hadgraft J. Penetration enhancement of ibuprofen from supersaturated solutions through human skin. Int J Pharm 2001; 212: 131-41.

[37] Iervolino M, Raghavan SL, Hadgraft J. Membrane penetration enhancement of ibuprofen using supersaturation. Int J Pharm 2000; 198: 229-38.

[38] Megrab NA, Williams AC, Barry BW. Oestradiol permeation through human skin and silastic membrane: effects of propylene glycol and supersaturation. J Control Release 1995; 36: 277-94.

[39] Moser K, Kriwet K, Kalia YN, Guy RH. Enhanced skin permeation of a lipophilic drug using supersaturated formulations. J Control Release 2001; 73: 245-53.

[40] Henmi T, Fujii M, Kikuchi K, Yamanobe N, Matsumoto M. Application of an oily gel formed by hydrogenated soybean phospholipids as a percutaneous absorption-type ointment base. Chem Pharm Bull (Tokyo) 1994; 42: 651-5.

[41] Kemken J, Ziegler A, Muller BW. Influence of supersaturation on the pharmacodynamic effect of bupranolol after dermal administration using microemulsions as vehicle. Pharm Res 1992; 9: 554-8.

[42] Cilurzo F, Minghetti P, Casiraghi A, Tosi L, Pagani S, Montanari L. Polymethacrylates as crystallization inhibitors in monolayer transdermal patches containing ibuprofen. Eur J Pharm Biopharm 2005; 60: 61-6.

[43] Raghavan SL, Trividic A, Davis AF, Hadgraft J. Crystallization of hydrocortisone acetate: influence of polymers. Int J Pharm 2001; 212: 213-21.

[44] Kim JH, Choi HK. Effect of additives on the crystallization and the permeation of ketoprofen from adhesive matrix. Int J Pharm 2002; 236: 81-5.

[45] Ma X, Taw J, Chiang C. Control of drug crystallisation in transdermal matrix system. Int J Pharm 1996; 142: 115-9.

[46] Waller DG, George CF. Prodrugs. Br J Clin Pharmacol 1989; 28 : 497-507.

[47] Saab AN, Sloan KB, Beall HD, Villaneuva R. Effect of aminomethyl (N-Mannich base) derivatization on the ability of S6acetyloxymethyl-6-mercaptopurine prodrug to deliver 6mercaptopurine through hairless mouse skin. J Pharm Sci 1990; 79: 1099-104.

[48] Beall H, Prankerd R, Sloan K. Transdermal delivery of 5-fluoruracil (5-FU) through hairless mouse skin by 1-alkyloxycarbonyl-5FU prodrugs: physicochemical characterization of prodrugs and correlations with transdermal delivery. Int J Pharm 1994; 111: 223-33.

[49] Rautio J, Nevalainen T, Taipale H, Vepsalainen J, Gynther J, Laine $\mathrm{K}$, et al. Piperazinylalkyl prodrugs of naproxen improve in vitro skin permeation. Eur J Pharm Sci 2000; 11: 157-63.

[50] Bonina FP, Puglia C, Barbuzzi T, de Caprariis P, Palagiano F, Rimoli $\mathrm{MG}$, et al. In vitro and in vivo evaluation of polyoxyethylene esters as dermal prodrugs of ketoprofen, naproxen and diclofenac. Eur $\mathbf{J}$ Pharm Sci 2001; 14: 123-34.
[51] Doh HJ, Cho WJ, Yong CS, Choi HG, Kim JS, Lee CH, et al. Synthesis and evaluation of Ketorolac ester prodrugs for transdermal delivery. J Pharm Sci 2003; 92: 1008-17.

[52] Moss GP, Gullick DR, Cox PA, Alexander C, Ingram MJ, Smart JD, et al. Design, synthesis and characterization of captopril prodrugs for enhanced percutaneous absorption. J Pharm Pharmacol 2006; 58: 167-77.

[53] Bourges JL, Lallemand F, Agla E, Besseghir K, Dumont JM, BenEzra D, et al. Evaluation of a topical cyclosporine A prodrug on corneal graft rejection in rats. Mol Vis 2006; 12: 1461-66.

[54] Stinchcomb AL, Paliwal A, Dua R, Imoto H, Woodard RW, Flynn GL. Permeation of buprenorphine and its 3-alkyl-ester prodrugs through human skin. Pharm Res 1996; 13: 1519-23.

[55] Ahmed S, Imai T, Otagiri M. Evaluation of stereoselective transdermal transport and concurrent cutaneous hydrolysis of several ester prodrugs of propranolol: mechanism of stereoselective permeation. Pharm Res 1996; 13: 1524-29.

[56] Majumdar S, Sloan KB. Topical delivery of N-alkyl-Nalkyloxycarbonylaminomethyl (NANAOCAM) prodrugs of theophylline (ThH). Int J Pharm 2007; 332: 64-71.

[57] De Rosa FS, Tedesco AC, Lopez RF, Pierre MB, Lange N, Marchetti $\mathrm{JM}$, et al. In vitro skin permeation and retention of 5-aminolevulinic acid ester derivatives for photodynamic therapy. J Control Release 2003; 89: 261-9.

[58] van den Akker JT, Holroyd JA, Vernon DI, Sterenborg HJ, Brown SB. Comparative in vitro percutaneous penetration of 5aminolevulinic acid and two of its esters through excised hairless mouse skin. Lasers Surg Med 2003; 33: 173-81.

[59] Swarbrick J, Lee G, Brom J, Gensmantel NP. Drug permeation through human skin II: Permeability of ionizable compounds. J Pharm Sci 1984; 7: 1352-55.

[60] Sarveiya V, Templeton JF, Benson HA. Ion-pairs of ibuprofen: increased membrane diffusion. J Pharm Pharmacol 2004; 56: 717-24.

[61] Megwa SA, Cross SE, Benson HA, Roberts MS. Ion-pair formation as a strategy to enhance topical delivery of salicylic acid. J Pharm Pharmacol 2000; 52: 919-28.

[62] Auner BG, Valenta C, Hadgraft J. Influence of lipophilic counterions in combination with phloretin and 6-ketocholestanol on the skin permeation of 5-aminolevulinic acid. Int J Pharm 2003; 255: 109-16.

[63] Kamal MA, Iimura N, Nabekura T, Kitagawa S. Enhanced skin permeation of diclofenac by ion-pair formation and further enhancement by microemulsion. Chem Pharm Bull.(Tokyo) 2007; 55: 368-71.

[64] Valenta C, Siman U, Kratzel M, Hadgraft J. The dermal delivery of lignocaine: influence of ion pairing. Int J Pharm 2000; 197: 77-85.

[65] Trotta M, Ugazio E, Peira E, Pulitano C. Influence of ion pairing on topical delivery of retinoic acid from microemulsions. J Control Release $2003 ; 86: 315-21$.

[66] Dimas DA, Dallas PP, Rekkas DM. Ion pair formation as a possible mechanism for the enhancement effect of lauric acid on the transdermal permeation of ondansetron. Pharm Dev Technol 2004; 9: 311-20.

[67] Chien YW, Jefferson DM, Conney JG, Lambert HJ. Controlled drug release from polymeric delivery devices V: Hydroxy group effects on drug release kinetics and thermodynamics. J Pharm Sci 1979; 68: 689-93.

[68] Stott PW, Williams AC, Barry BW. Transdermal delivery from eutectic systems: enhanced permeation of a model drug, ibuprofen. J Control Release 1998; 50: 297-308

[69] Nyqvist-Mayer AA, Brodin AF, Frank SG. Drug release studies on an oil-water emulsion based on a eutectic mixture of lidocaine and prilocaine as the dispersed phase. J Pharm Sci 1986; 75: 365-73.

[70] Zimmer R, Ashburn MA. Noninvasive drug delivery. Compr Ther 2001; 27: 293-301.

[71] Schecter AK, Pariser DM, Pariser RJ, Ling MR, Stewart D, Sadick NS. Randomized, double-blind, placebo-controlled study evaluating the lidocaine/tetracaine patch for induction of local anesthesia prior to minor dermatologic procedures in geriatric patients. Dermatol Surg 2005; 31: 87-291.

[72] Doshi SN, Friedman PM, Marquez DK, Goldberg LH. Thirty-minute application of the S-Caine peel prior to nonablative laser treatment. Dermatol Surg 2003; 29: 1008-11.

[73] Sethna NF, Verghese ST, Hannallah RS, Solodiuk JC, Zurakowski D, Berde CB. A randomized controlled trial to evaluate S-Caine patch for reducing pain associated with vascular access in children. Anesthesiology 2005; 102: 403-8. 
[74] Kaplun-Frischoff Y, Touitou E. Testosterone skin permeation enhancement by menthol through formation of eutectic with drug and interaction with skin lipids. J Pharm Sci 1997; 86:1394-9.

[75] Stott PW, Williams AC, Barry BW. Mechanistic study into the enhanced transdermal permeation of a model beta-blocker, propranolol, by fatty acids: a melting point depression effect. Int J Pharm 2001; 219: 161-76.

[76] Fourie L, Breytenbach JC, Du Plessis J, Goosen C, Swart H, Hadgraft J. Percutaneous delivery of carbamazepine and selected $\mathrm{N}$-alkyl and N-hydroxyalkyl analogues. Int J Pharm 2004; 279: 59-66.

[77] Benson HA. Transfersomes for transdermal drug delivery. Expert Opin Drug Deliv 2006; 3: 727-37.

[78] Kaparissides C, Alexandridou S, Kotti K, Chaitidou S. Recent Advances in Novel Drug Delivery Systems. AZoJono [serial on the internet]. 2006 Mar 2005; [cited 2007 June 15] Available from: http://www.azonano.com/Details.asp?ArticleID=1538.

[79] Vemuri S, Rhodes CT. Preparation and characterization of liposomes as therapeutic delivery systems: a review. Pharm Acta Helv 1995; 70 : 95-111.

[80] Mezei M, Gulasekharam V. Liposomes-a selective drug delivery system for the topical route of administration: gel dosage form. $\mathbf{J}$ Pharm Pharmacol 1982; 34: 473-4.

[81] Foldvari M, Gesztes A, Mezei M. Dermal drug delivery by liposome encapsulation: clinical and electron microscopic studies. J Microencapsul 1990; 7: 479-89.

[82] Du Plessis J, Ramachandran C, Weiner N, Muller DG. Influence of particle size of liposomes on deposition of drug into skin. Int J Pharm 1994; 103: 277-82.

[83] Kirjavainen M, Urtti A, Jaaskelainen I, Suhonen TM, Paronen P, Valjakka-Koskela $\mathrm{R}$, et al. Interaction of liposomes with human skin in vitro-the influence of lipid composition and structure. Biochim Biophys Acta 1996; 1304: 179-89.

[84] El Maghraby GM, Williams AC, Barry BW. Skin delivery of oestradiol from lipid vesicles: importance of liposome structure. Int $\mathbf{J}$ Pharm 2000; 204: 159-69.

[85] El Maghraby GM, Williams AC, Barry BW. Can drug-bearing liposomes penetrate intact skin. Pharm Pharmacol 2006; 58: 415-29.

[86] El Maghraby GM, Williams AC, Barry BW. Skin hydration and possible shunt route penetration in controlled estradiol delivery from ultradeformable and standard liposomes. J Pharm Pharmacol 2001; 53: 1311-22.

[87] Wohlrab W, Lasch J. Penetration kinetics of liposomal hydrocortisone in human skin. Dermatologica 1987; 174: 18-22.

[88] Wohlrab W, Lasch J. The effect of liposomal incorporation of topically applied hydrocortisone on its serum concentration and urinary excretion. Dermatol Monatsschr 1989; 175: 348-52.

[89] Katahira N, Murakami T, Kugai S, Yata N, Takano M. Enhancement of topical delivery of a lipophilic drug from charged multilamellar liposomes. J Drug Target 1999; 6: 405-14.

[90] Egbaria K, Ramachandran C, Weiner N. Topical delivery of ciclosporin: evaluation of various formulations using in vitro diffusion studies in hairless mouse skin. Skin Pharmacol 1990; 3: 21-8.

[91] Lieb LM, Ramachandran C, Egbaria K, Weiner N. Topical delivery enhancement with multilamellar liposomes into pilosebaceous units: I. In vitro evaluation using fluorescent techniques with the hamster ear model. J Invest Dermatol 1992; 99: 108-13.

[92] Manconi M, Sinico C, Valenti D, Loy G, Fadda AM. Niosomes as carriers for tretinoin. I. Preparation and properties. Int J Pharm 2002; 234: 237-48.

[93] Agarwal R, Katare OP, Vyas SP. Preparation and in vitro evaluation of liposomal/niosomal delivery systems for antipsoriatic drug dithranol. Int J Pharm 2001; 228: 43-52.

[94] Cevc G, Blume G. Lipid vesicles penetrate into intact skin owing to the transdermal osmotic gradients and hydration force. Biochim Biophys Acta 1992; 1104: 226-32.

[95] Elsayed MM, Abdallah OY, Naggar VF, Khalafallah NM. Lipid vesicles for skin delivery of drugs: reviewing three decades of research. Int J Pharm 2007; 332: 1-16.

[96] Cevc G, Blume G. New, highly efficient formulation of diclofenac for the topical, transdermal administration in ultradeformable drug carriers, Transfersomes. Biochim Biophys Acta 2001; 1514: 191-205.

[97] Cevc G, Blume G. Biological activity and characteristics of triamcinolone-acetonide formulated with the self-regulating drug carriers, Transfersomes. Biochim Biophys Acta 2003; 1614: 156-64.

[98] Jain S, Jain P, Umamaheshwari RB, Jain NK. Transfersomes--a novel vesicular carrier for enhanced transdermal delivery: development, characterization, and performance evaluation. Drug Dev Ind Pharm 2003; 29: 1013-26.

[99] Trotta M, Peira E, Carlotti ME, Gallarate M. Deformable liposomes for dermal administration of methotrexate. Int J Pharm 2004; 270: 119-25.

[100] Elsayed MM, Abdallah OY, Naggar VF, Khalafallah NM. Deformable liposomes and ethosomes: mechanism of enhanced skin delivery. Int J Pharm 2006; 322: 60-6.

[101] Elsayed MM, Abdallah OY, Naggar VF, Khalafallah NM. Deformable liposomes and ethosomes as carriers for skin delivery of ketotifen. Pharmazie 2007; 62: 133-7.

[102] Jain S, Tiwary AK, Jain NK. Sustained and targeted delivery of an anti-HIV agent using elastic liposomal formulation: mechanism of action. Curr Drug Deliv 2006; 3:157-66.

[103] Garg M, Mishra D, Agashe H, Jain NK. Ethinyloestradiol loaded ultraflexible liposomes: pharmacokinetics and pharmacodynamics. J Pharm Pharmacol 2006; 58: 459-68.

[104] Oh YK, Kim MY, Shin JY, Kim TW, Yun MO, Yang SJ, et al. Skin permeation of retinol in Tween 20-based deformable liposomes: invitro evaluation in human skin and keratinocyte models. J Pharm Pharmacol 2006; 58: 161-6.

[105] Trotta M, Peira E, Debernardi F, Gallarate M. Elastic liposomes for skin delivery of dipotassium glycyrrhizinate. Int J Pharm 2002; 241: 319-27.

[106] Cevc G, Gebauer D, Stieber J, Schatzlein A, Blume G. Ultraflexible vesicles, Transfersomes, have an extremely low pore penetration resistance and transport therapeutic amounts of insulin across the intact mammalian skin. Biochim Biophys Acta 1998; 1368: 201-15.

[107] Guo J, Ping Q, Zhang L. Transdermal delivery of insulin in mice by using lecithin vesicles as a carrier. Drug Deliv 2000; 7: 113-6.

[108] Kim A, Lee EH, Choi SH, Kim CK. In vitro and in vivo transfection efficiency of a novel ultradeformable cationic liposome. Biomaterials 2004; 25: 305-13.

[109] Lee EH, Kim A, Oh YK, Kim CK. Effect of edge activators on the formation and transfection efficiency of ultradeformable liposomes. Biomaterials 2005; 26: 205-10.

[110] Vyas SP, Singh RP, Jain S, Mishra V, Mahor S, Singh P, et al. Nonionic surfactant based vesicles (niosomes) for non-invasive topical genetic immunization against hepatitis B. Int J Pharm 2005; 296: 806.

[111] Gupta PN, Mishra V, Rawat A, Dubey P, Mahor S, Jain S, et al. Noninvasive vaccine delivery in transfersomes, niosomes and liposomes: a comparative study. Int J Pharm 2005; 293: 73-82.

[112] Mishra D, Dubey V, Asthana A, Saraf DK, Jain NK. Elastic liposomes mediated transcutaneous immunization against Hepatitis B. Vaccine 2006; 24: 4847-55.

[113] Rother M, Lavins BJ, Kneer W, Lehnhardt K, Seidel EJ, Mazgareanu S. Efficacy and safety of epicutaneous ketoprofen in Transfersome(R)(IDEA-033) versus oral celecoxib and placebo in osteoarthritis of the knee: multicentre randomised controlled trial. Ann Rheum Dis 2007; 66:1178-83.

[114] Touitou E, Alkabes M, Dayan N, Eliaz M. Ethosomes: novel vesicular carriers for enhanced skin delivery. Pharm Res 1997; 14: S305.

[115] Touitou E, Dayan N, Bergelson L, Godin B, Eliaz M. Ethosomes novel vesicular carriers for enhanced delivery: characterization and skin penetration properties. J Control Release 2000; 65: 403-18.

[116] Dayan N, Touitou E. Carriers for skin delivery of trihexyphenidyl $\mathrm{HCl}$ : ethosomes vs liposomes. Biomaterials 2000; 21: 1879-85.

[117] Friend D, Catz P, Heller J, Reid J, Baker R. Transdemal delivery of levonorgesterol I. Alkanols as permeation enhancers. J Control Release $1988 ; 7: 243-50$.

[118] Blume A, Jansen M, Ghyczy M, Gareis J. Interaction of phospholipid liposomes with lipid model mixtures for startum corneum lipids. Int J Pharm 1993; 99: 219-20.

[119] Touitou E, Godin B, Weiss C. Enhanced delivery of drugs into and across the skin by ethosomal carriers. Drug Dev Res 2000; 50: 40615.

[120] Lodzki M, Godin B, Rakou L, Mechoulam R, Gallily R, Touitou E. Cannabidiol-transdermal delivery and anti-inflammatory effect in a murine model. J Control Rel 2003; 93: 377-87.

[121] Horwitz E, Pisanty S, Czerninski R, Helser M, Eliav E, Touitou E. A clinical evaluation of a novel liposomal carrier for acyclovir in the topical treatment of recurrent herpes labialis. Oral Surg Oral Med Oral Pathol Oral Radiol Endod 1999; 87: 700-5.

[122] Muller RH, Keck CM. Drug delivery to the brain--realization by novel drug carriers. J Nanosci Nanotechnol 2004; 4: 471-83. 
[123] Yu BT, Sun X, Zhang ZR. Enhanced liver targeting by synthesis of N1-stearyl-5-Fu and incorporation into solid lipid nanoparticles. Arch Pharm Res 2003; 26: 1096-101.

[124] Liu J, Hu W, Chen H, Ni Q, Xu H, Yang X. Isotretinoin-loaded solid lipid nanoparticles with skin targeting for topical delivery. Int $\mathrm{J}$ Pharm 2007; 328: 191-5.

[125] Muller RH, Radtke M, Wissing SA. Solid lipid nanoparticles (SLN) and nanostructured lipid carriers (NLC) in cosmetic and dermatological preparations. Adv Drug Deliv Rev 2002; 54: S131-55.

[126] Maia CS, Mehnert W, Schafer-Korting M. Solid lipid nanoparticles as drug carriers for topical glucocorticoids. Int J Pharm 2000; 196: $165-7$.

[127] Jenning V, Schafer-Korting M, Gohla S. Vitamin A-loaded solid lipid nanoparticles for topical use: drug release properties. J Control Release 2000; 66: 115-26.

[128] Wissing SA, Muller RH. Cosmetic applications for solid lipid nanoparticles (SLN). Int J Pharm 2003; 254: 65-8.

[129] Wissing S, Muller R. The development of an improved carrier system for sunscreen formulations based on crystalline lipid nanoparticles. Int J Pharm 2002; 242: 373-5.

[130] Singh S, Singh J. Transdermal drug delivery by passive diffusion and iontophoresis: a review. Med Res Rev 1993; 13: 569-621.

[131] Barry BW. Mode of action of penetration enhancers in human skin. J Control Release. 1987; 6: 85-97.

[132] Marjukka Suhonen T, Bouwstra JA, Urtti A. Chemical enhancement of percutaneous absorption in relation to stratum corneum structural alterations. J Control Release 1999; 59:149-61.

[133] Trommer H, Neubert RH. Overcoming the stratum corneum: the modulation of skin penetration. A review. Skin Pharmacol Physiol 2006; 19: 106-21.

[134] Touitou E. Drug delivery across the skin. Expert Opin Biol Ther 2002; 2: 723-33.

[135] Heard CM, Kung D, Thomas CP. Skin penetration enhancement of mefenamic acid by ethanol and 1,8-cineole can be explained by the 'pull' effect. Int J Pharm 2006; 321: 167-70.

[136] Hadgraft J. Skin, the final frontier. Int J Pharm 2001; 224: 1-18.

[137] Pershing LK, Lambert LD, Knutson K. Mechanism of ethanolenhanced estradiol permeation across human skin in vivo. Pharm Res 1990; 7: 170-5.

[138] Megrab NA, Williams AC, Barry BW. Oestradiol permeation across human skin, silastic and snake skin membranes: the effects of ethanol/water co-solvent systems. Int J Pharm 1995; 116: 101-12.

[139] Stoughton RB. Enhanced percutaneous penetration with 1dodecylazacycloheptan-2-one. Arch Dermatol 1982; 118: 474-7.

[140] Ogiso T, Ito Y, Iwaki M, Atago H. Absorption of indomethacin and its calcium salt through rat skin: effect of penetration enhancers and relationship between in vivo and in vitro penetration. J Pharmacobiodyn 1986; 9: 517-25.

[141] Drabick JJ, Glasspool-Malone J, King A, Malone RW. Cutaneous transfection and immune responses to intradermal nucleic acid vaccination are significantly enhanced by in vivo electropermeabilization. Mol Ther 2001; 3: 249-55.

[142] Sugibayashi K, Hosoya K, Morimoto Y, Higuchi WI. Effect of the absorption enhancer, Azone, on the transport of 5-fluorouracil across hairless rat skin. J Pharm Pharmacol 1985; 37: 578-80.

[143] Stoughton RB. Enhanced percutaneous penetration with 1dodecylazacycloheptan-2-one. Arch Dermatol 1982; 118: 474-7.

[144] Anigbogu ANC, Williams AC, Barry BW, Edwards HGM. Fourier transform ramen spectroscopy of interactions between the penetration enhancer dinmethyl sulfoxide and human stratum corneum. Int $\mathbf{J}$ Pharm 1995; 125: 265-82.

[145] Williams AC, Barry BW. Skin absorption enhancers. Crit Rev Ther Drug Carrier Syst 1992; 9: 305-53.

[146] Williams AC, Barry BW. Penetration enhancers. Adv Drug Deliv Rev 2004; 56: 603-18.

[147] Tashtoush BM, Al-Safi SA, Al-Fanek KJ. Azathioprine transport through rat skin and its immunosuppressive effect. Pharmazie 2004; 59: $143-6$.

[148] Liu H, Li S, Wang Y, Yao H, Zhang Y. Effect of vehicles and enhancers on the topical delivery of cyclosporin A. Int J Pharm 2006; 311: 182-6.

[149] Reddy LH, Ghosh B. Enhancer aided in vitro permeation of atenolol and prazosin hydrochloride through mice skin. Indian J Exp Biol 2001; 39: 47-51.
[150] Jantharaprapap R, Stagni G. Effects of penetration enhancers on in vitro permeability of meloxicam gels. Int J Pharm 2007; 343(1-2): 26-33.

[151] Iliev D, Hinnen U, Elsner P. Skin roughness is negatively correlated to irritation with DMSO, but not with $\mathrm{NaOH}$ and SLS. Exp Dermatol 1997; 6: 157-160

[152] Hussain AS, Ritschel WA. Influence of dimethylacetamide, N-N diethyl-m-toluamide and 1-dodecylazacycloheptan-2-one on ex vivo permeation of phosphonoformic acid through rat skin. Methods Find Exp Clin Pharmacol 1988; 10: 691-4.

[153] Southwell D, Barry BW. Penetration enhancers for human skin mode of action of 2-pyrrolidone and dimethylformamide on partition and diffusion of model compounds water, $\mathrm{n}$-alcohols, and caffeine. $\mathrm{J}$ Invest Dermatol 1983; 80: 507-14.

[154] Barry BW, Bennett SL. Effect of penetration enhancers on the permeation of mannitol, hydrocortisone and progesterone through human skin. J Pharm Pharmacol 1987; 39: 535-46.

[155] Aungst BJ, Rogers NJ, Shefter E. Enhancement of naloxone penetration through human skin in vitro using fatty acids, fatty alcohols, surfactants, sulfoxides and amides. J Pharmaceut 1986; 33: 225-34.

[156] Jiang SJ, Zhou XJ. Examination of the mechanism of oleic acidinduced percutaneous penetration enhancement: an ultrastructural study. Biol Pharm Bull 2003; 26: 66-8.

[157] Pierre MB, Ricci E Jr, Tedesco AC, Bentley MV. Oleic acid as optimizer of the skin delivery of 5-aminolevulinic acid in photodynamic therapy. Pharm Res 2006; 23: 360-6.

[158] Aungst BJ, Blake JA, Hussain MA. Contributions of drug solubilisation, partitioning, barrier disruption and solvent permeation to the enhancement of skin permeation of various compounds with fatty acids and amines. Pharm Res 1990; 7: 712-8.

[159] Bond JR, Barry BW. Limitations of hairless mouse skin as a model for in vitro permeation studies through human skin: hydration damage. J Invest Dermatol 1988; 90: 486-9.

[160] Goodman M, Barry BW. Action of penetration enhancers on human skin as assessed by the permeation of model drugs 5-fluorouracil and estradiol. I. Infinite dose technique. J Invest Dermatol 1988; 91: 323 7.

[161] Kanikkannan N, Singh M. Skin permeation enhancement effect and skin irritation of saturated fatty alcohols. Int J Pharm 2002; 248: 21928

[162] Wang MY, Yang YY, Heng PW. Skin permeation of physostigmine from fatty acids-based formulations: evaluating the choice of solvent. Int J Pharm 2005; 290: 25-36.

[163] Femenia-Font A, Balaguer-Fernandez C, Merino V, Rodilla V, Lopez-Castellano A. Effect of chemical enhancers on the in vitro percutaneous absorption of sumatriptan succinate. Eur J Pharm Biopharm 2005; 61: 50-5.

[164] Aungst BJ, Blake JA, Rogers NJ, Hussain MA. Transdermal oxymorphone formulation development and methods for evaluating flux and lag times for two skin permeation-enhancing vehicles. J Pharm Sci 1990; 79: 1072-6.

[165] Nanayakkara GR, Bartlett A, Forbes B, Marriott C, Whitfield PJ, Brown MB. The effect of unsaturated fatty acids in benzyl alcohol on the percutaneous permeation of three model penetrants. Int J Pharm 2005; 301: 129-39.

[166] Jantharaprapap R, Stagni G. Effects of penetration enhancers on in vitro permeability of meloxicam gels. Int J Pharm 2007. In Press.

[167] Rastogi SK, Singh J. Effect of chemical penetration enhancer and iontophoresis on the in vitro percutaneous absorption enhancement of insulin through porcine epidermis. Pharm Dev Technol 2005; 10: 97 104.

[168] Rawlings AV, Harding CR. Moisturization and skin barrier function. Dermatol Ther 2004; 17: 43-8.

[169] Koizumi A, Fujii M, Kondoh M, Watanabe Y. Effect of N-methyl-2pyrrolidone on skin permeation of estradiol. Eur J Pharm Biopharm 2004; 57: 473-8.

[170] Babu RJ, Pandit JK. Effect of penetration enhancers on the release and skin permeation of bupranolol from reservoir-type transdermal delivery systems. Int J Pharm 2005; 288: 325-34.

[171] Shishu, Aggarwal N. Preparation of hydrogels of griseofulvin for dermal application. Int J Pharm 2006; 326: 20-4.

[172] Leira HL, Tiltnes A, Svendsen K, Vetlesen L. Irritant cutaneous reactions to N-methyl-2-pyrrolidone (NMP). Contact Dermatitis 1992; $27: 148-50$

[173] Baby AR, Lacerda AC, Velasco MV, Lopes PS, Kawano Y, Kaneko TM. Evaluation of the interaction of surfactants with stratum cor- 
neum model membrane from Bothrops jararaca by DSC. Int J Pharm 2006; 317: 7-9.

[174] Nokhodchi A, Shokri J, Dashbolaghi A, Hassan-Zadeh D, Ghafourian T, Barzegar-Jalali M. The enhancement effect of surfactants on the penetration of lorazepam through rat skin. Int J Pharm 2003; 250: 359-69.

[175] Lavon I, Grossman N, Kost J. The nature of ultrasound-SLS synergism during enhanced transdermal transport. J Control Release 2005; 107: 484-94.

[176] Li GL, de Vries JJ, van Steeg TJ, van den Bussche H, Maas HJ, Reeuwijk HJ, et al. Transdermal iontophoretic delivery of apomorphine in patients improved by surfactant formulation pretreatment. $\mathrm{J}$ Control Release 2005; 101: 199-208.

[177] Kang L, Poh AL, Fan SK, Ho PC, Chan YW, Chan SY. Reversible effects of permeation enhancers on human skin. Eur J Pharm Biopharm 2007; 67: 149-55.

[178] Williams AC, Barry BW. Terpenes and the lipid-protein-partitioning theory of skin penetration enhancement. Pharm Res 1991; 8: 17-24.

[179] Narishetty ST, Panchagnula R. Transdermal delivery of zidovudine: effect of terpenes and their mechanism of action. J Control Release 2004; 95: 367-79.

[180] Cornwell P, Barry BW, Bouwstra JA, Gooris GS. Modes of action of terpene penetration enhancers in human skin; differential scanning calorimetry, small-angle X-ray diffraction and enhancer uptake studies. Int J Pharm 1996; 127: 9-26.

[181] Godwin DA, Michniak BB. Influence of drug lipophilicity on terpenes as transdermal penetration enhancers. Drug Dev Ind Pharm 1999; 25: $905-15$.

[182] Nokhodchi A, Sharabiani K, Rashidi MR, Ghafourian T. The effect of terpene concentrations on the skin penetration of diclofenac sodium. Int J Pharm 2007; 335: 97-105.

[183] Fujii M, Takeda Y, Yoshida M, Matsumoto M, Watanabe Y. Enhancement effect of p-menthane-3,8-diol on in vitro permeation of antipyrine and indomethacin through Yucatan micropig skin. Drug Dev Ind Pharm 2004; 30: 673-7.

[184] Williams AC, Barry BW. Terpenes and the lipid-protein-partitioning theory of skin penetration enhancement. Pharm Res 1991; 8: 17-24.

[185] Ota Y, Hamada A, Nakano M, Saito H. Evaluation of percutaneous absorption of midazolam by terpenes. Drug Metab Pharmacokinet 2003; 18: 261-6.

[186] Femenia-Font A, Balaguer-Fernandez C, Merino V, Rodilla V, Lopez-Castellano A. Effect of chemical enhancers on the in vitro percutaneous absorption of sumatriptan succinate. Eur J Pharm Biopharm 2005; 61: 50-5.

[187] Amnuaikit C, Ikeuchi I, Ogawara K, Higaki K, Kimura T. Skin permeation of propranolol from polymeric film containing terpene enhancers for transdermal use. Int J Pharm 2005; 289: 167-78.

[188] Monti D, Chetoni P, Burgalassi S, Najarro M, Saettone MF, Boldrini E. Effect of different terpene-containing essential oils on permeation of estradiol through hairless mouse skin. Int J Pharm 2002; 237: 20914.

[189] Fang JY, Tsai TH, Lin YY, Wong WW, Wang MN, Huang JF. Transdermal delivery of tea catechins and theophylline enhanced by terpenes: a mechanistic study. Biol Pharm Bull 2007; 30: 343-9.

[190] Fujii M, Buyuktimkin S, Buyuktimkin N, Rytting JH. Enhancement of skin permeation of miconazole by phospholipid and dodecyl 2(N,N-dimethyl amino)propionate (DDAIP). Int J Pharm 2002; 234: 121-8.

[191] Kato A, Ishibashi Y, Miyake Y. Effect of egg yolk lecithin on transdermal delivery of bunazosin hydrochloride. J Pharm Pharmacol 1987; 39: 399-400.

[192] Tenjarla SN, Kasina R, Puranajoti P, Omar MS, Harris WT. Synthesis and evaluation of $\mathrm{N}$-acetylprolinate esters - novel skin penetration enhancers. Int J Pharm 1999; 192: 147-58

[193] Valenta C, Wedenig S. Effects of penetration enhancers on the invitro percutaneous absorption of progesterone. J Pharm Pharmacol 1997; 49: 955-9.

[194] Tenjarla SN, Kasina R, Puranajoti P, Omar MS, Harris WT. Synthesis and evaluation of $\mathrm{N}$-acetylprolinate esters - novel skin penetration enhancers. Int J Pharm 1999; 192: 147-58.

[195] Song Y, Xiao C, Mendelsohn R, Zheng T, Strekowski L, Michniak B. Investigation of iminosulfuranes as novel transdermal penetration enhancers: enhancement activity and cytotoxicity. Pharm Res 2005; 22: $1918-25$.

[196] Barrow DJ Jr, Chandrasekaran S, Heerklotz HH, Henary MM, Michniak BB, Nguyen PM, et al. Mechanistic studies on percutaneous penetration enhancement by N-(4-halobenzoyl)-S,S-dimethyliminosulfuranes. J Lipid Res 2005; 46: 2192-201.

[197] Hadgraft J, Peck J, Williams DG, Pugh WJ, Allan G. Mechanisms of action of skin penetration enhancers/retarders: azone and analogues. Int J Pharm 1996; 141: 17-25.

[198] Tsai JC, Shen LC, Sheu HM, Lu CC. Tape stripping and sodium dodecyl sulfate treatment increase the molecular weight cutoff of polyethylene glycol penetration across murine skin. Arch Dermatol Res 2003; 295: 169-74.

[199] van den Akker JT, Iani V, Star WM, Sterenborg HJ, Moan J. Topical application of 5-aminolevulinic acid hexyl ester and 5-aminolevulinic acid to normal nude mouse skin: differences in protoporphyrin IX fluorescence kinetics and the role of the stratum corneum. Photochem Photobiol 2000; 72: 681-9.

[200] Lee WR, Shen SC, Wang KH. The effect of laser treatment on skin to enhance and control transdermal delivery of 5-fluorouracil. J Pharm Sci 2002; 9: 1613-26.

[201] Fang JY, Lee WR, Shen SC, Fang YP, Hu CH. Enhancement of topical 5-aminolaevulinic acid delivery by erbium:YAG laser and microdermabrasion: a comparison with iontophoresis and electroporation. Br J Dermatol 2004; 151: 132-40.

[202] Shen SC, Lee WR, Fang YP, Hu CH, Fang JY. In vitro percutaneous absorption and in vivo protoporphyrin IX accumulation in skin and tumors after topical 5-aminolevulinic acid application with enhancement using an erbium:YAG laser. J Pharm Sci 2006; 95: 929-38.

[203] Nelson JS, McCullough JL, Glenn TC, Wright WH, Liaw LH, Jacques SL. Mid-infrared laser ablation of stratum corneum enhances in vitro percutaneous transport of drugs. J Invest Dermatol 1991; 97 : 874-9.

[204] Lee WR, Shen SC, Lai HH, Hu CH, Fang JY. Transdermal drug delivery enhanced and controlled by erbium:YAG laser: a comparative study of lipophilic and hydrophilic drugs. J Control Release 2001; 75: 155-66.

[205] Lee WR, Shen SC, Liu CR, Fang CL, Hu CH, Fang JY. Erbium:YAG laser-mediated oligonucleotide and DNA delivery via the skin: an animal study. J Control Release 2006; 115: 344-53.

[206] Fang JY, Lee WR, Shen SC, Wang HY, Fang CL, Hu CH. Transdermal delivery of macromolecules by erbium:YAG laser. J Control Release 2004; 100: 75-85.

[207] Svedman P, Lundin S, Svedman C. Administration of antidiuretic peptide (DDAVP) by way of suction de-epithelialised skin. Lancet 1991; 337: 1506-9.

[208] Westerling D, Hoglund P, Lundin S, Svedman P. Transdermal administration of morphine to healthy subjects. Br J Clin Pharmacol 1994; 37: 571-6.

[209] Lundin S, Svedman P, Hoglund P, Jonsson K, Broeders A, Melin P. Absorption of an oxytocin antagonist (antocin) and a vasopressin analogue (dDAVP) through a standardized skin erosion in volunteers. Pharm Res 1995; 12: 2024-9.

[210] Sintov AC, Krymberk I, Daniel D, Hannan T, Sohn Z, Levin G. Radiofrequency-driven skin microchanneling as a new way for electrically assisted transdermal delivery of hydrophilic drugs. J Control Release 2003; 89: 311-20.

[211] Badkar AV, Smith AM, Eppstein JA, Banga AK. Transdermal Delivery of Interferon Alpha-2B using Microporation and Iontophoresis in Hairless Rats. Pharm Res 2007; 24: 1389-95.

[212] Herndon TO, Gonzalez S, Gowrishankar TR, Anderson RR, Weaver JC. Transdermal microconduits by microscission for drug delivery and sample acquisition. BMC Med 2004; 2: 12.

[213] Henry S, McAllister DV, Allen MG, Prausnitz MR. Microfabricated microneedles: a novel approach to transdermal drug delivery. J Pharm Sci 1998; 87: 922-5.

[214] Tao SL, Desai TA. Microfabricated drug delivery systems: from particles to pores. Adv Drug Deliv Rev 2003; 55: 315-28.

[215] Hilt JZ, Peppas NA. Microfabricated drug delivery devices. Int J Pharm 2005; 306: 15-23.

[216] Ito Y, Hagiwara E, Saeki A, Sugioka N, Takada K. Feasibility of microneedles for percutaneous absorption of insulin. Eur J Pharm Sci 2006; 29: 82-8.

[217] Ito Y, Yoshimitsu J, Shiroyama K, Sugioka N, Takada K. Selfdissolving microneedles for the percutaneous absorption of EPO in mice. J Drug Target 2006; 14: 255-61.

[218] Wang PM, Cornwell M, Hill J, Prausnitz MR. Precise microinjection into skin using hollow microneedles. J Invest Dermatol 2006; 126 : 1080-7. 
[219] Miyano T, Tobinaga Y, Kanno T, Matsuzaki Y, Takeda H, Wakui M, et al. Sugar micro needles as transdermic drug delivery system. Biomed Microdevices 2005; 7: 185-8.

[220] Kolli CS, Banga AK. Characterization of Solid Maltose Microneedles and their Use for Transdermal Delivery. Pharm Res 2007. In Press.

[221] Park JH, Allen MG, Prausnitz MR. Biodegradable polymer microneedles: fabrication, mechanics and transdermal drug delivery. J Control Release 2005; 104: 51-66.

[222] Park JH, Allen MG, Prausnitz MR. Polymer microneedles for controlled-release drug delivery. Pharm Res 2006; 23:1008-19.

[223] Perennes F, Marmiroli B, Matteucci M, Tormen M, Vaccari L, Di Fabrizio E. Sharp Beveled Tip Hollow Microneedle Arrays Fabricated by LIGA and 3D Soft Lithography with Polyvinyl Alcohol. J Micromech Microeng 2006; 16: 473-9.

[224] McAllister DV, Wang PM, Davis SP, Park JH, Canatella PJ, Allen MG, et al. Microfabricated needles for transdermal delivery of macromolecules and nanoparticles: fabrication methods and transport studies. Proc Natl Acad Sci USA 2003; 100: 13755-60.

[225] Kaushik S, Hord AH, Denson DD, McAllister DV, Smitra S, Allen $\mathrm{MG}$, et al. Lack of pain associated with microfabricated microneedles. Anesth Analg 2001; 92: 502-4.

[226] Gill HS, Prausnitz MR. Coating Formulations for Microneedles. Pharm Res 2007; 24: 1369-80.

[227] Matriano JA, Cormier M, Johnson J, Young WA, Buttery M, Nyam $\mathrm{K}$, et al. Macroflux microprojection array patch technology: a new and efficient approach for intracutaneous immunization. Pharm Res 2002; 19: 63-70.

[228] Gardeniers JGE, Luttge R, Berenschot EJW. Silicon micromachioned hollow microneedles for transdermal liquid transport. J Microelect Systems 2003; 12: 855-62.

[229] Davis SP, Martanto W, Allen MG, Prausnitz MR. Hollow metal microneedles for insulin delivery to diabetic rats. IEEE Trans Biomed Eng 2005; 52: 909-15.

[230] Mikszta JA, Dekker JP,3rd, Harvey NG, Dean CH, Brittingham JM, Huang $\mathrm{J}$, et al. Microneedle-based intradermal delivery of the anthrax recombinant protective antigen vaccine. Infect Immun 2006; 74 : 6806-10.

[231] Coulman SA, Barrow D, Anstey A, Gateley C, Morrissey A, Wilke $\mathrm{N}$, et al. Minimally invasive cutaneous delivery of macromolecules and plasmid DNA via microneedles. Curr Drug Deliv 2006; 3: 65-75.

[232] Xie Y, Xu B, Gao Y. Controlled transdermal delivery of model drug compounds by MEMS microneedle array. Nanomed: Nanotech Biol Med 2005; 1: 184-90.

[233] Cormier M, Johnson B, Ameri M, Nyam K, Libiran L, Zhang DD, et al. Transdermal delivery of desmopressin using a coated microneedle array patch system. J Control Release 2004; 97: 503-11.

[234] Martanto W, Davis SP, Holiday NR, Wang J, Gill HS, Prausnitz MR. Transdermal delivery of insulin using microneedles in vivo. Pharm Res 2004; 21 : 947-52.

[235] Nordquist L, Roxhed N, Griss P, Stemme G. Novel microneedle patches for active insulin delivery are efficient in maintaining glycaemic control: an initial comparison with subcutaneous administration. Pharm Res 2007; 24: 1381-8.

[236] Sivamani RK, Stoeber B, Wu GC, Zhai H, Liepmann D, Maibach H. Clinical microneedle injection of methyl nicotinate: stratum corneum penetration. Skin Res Technol 2005; 11: 152-6.

[237] Widera G, Johnson J, Kim L, Libiran L, Nyam K, Daddona PE, et al. Effect of delivery parameters on immunization to ovalbumin following intracutaneous administration by a coated microneedle array patch system. Vaccine 2006; 24: 1653-64.

[238] Mikszta JA, Alarcon JB, Brittingham JM, Sutter DE, Pettis RJ, Harvey NG. Improved genetic immunization via micromechanical disruption of skin-barrier function and targeted epidermal delivery. Nat Med 2002; 8: 415-9.

[239] Teo MA, Shearwood C, Ng KC, Lu J, Moochhala S. In vitro and in vivo characterization of MEMS microneedles. Biomed Microdevices 2005; 7: 47-52.

[240] Smart WH, Subramanian K. The use of silicon microfabrication technology in painless blood glucose monitoring. Diabetes Technol Ther 2000; 2: 549-59.

[241] Prausnitz MR. Microneedles for transdermal drug delivery. Adv Drug Deliv Rev 2004; 56: 581-7.

[242] Martanto W, Moore JS, Kashlan O, Kamath R, Wang PM, O'Neal $\mathrm{JM}$, et al. Microinfusion using hollow microneedles. Pharm Res 2006; 23: 104-13.
[243] Fehr MK, Hornung R, Schwarz VA, Simeon R, Haller U, Wyss P. Photodynamic therapy of vulvar intraepithelial neoplasia III using topically applied 5-aminolevulinic acid. Gynecol Oncol 2001 Jan; 80: 62-6.

[244] Schuetz YB, Naik A, Guy RH, Kalia YN. Emerging strategies for the transdermal delivery of peptide and protein drugs. Expert Opin Drug Deliv 2005; 2: 533-48.

[245] Merino G, Kalia YN, Guy RH. Ultrasound-enhanced transdermal transport. J Pharm Sci 2003; 92: 1125-37.

[246] Mitragotri S. Healing sound: the use of ultrasound in drug delivery and other therapeutic applications. Nat Rev Drug Discov 2005; 4: 255-60.

[247] Mitragotri S, Kost J. Low-frequency sonophoresis: a review. Adv Drug Deliv Rev 2004; 56: 589-601.

[248] Meidan VM, Walmsley AD, Irwin WJ. Phonophoresis - is it a Reality? Int J Pharm 1995; 118: 129-49.

[249] Tezel A, Mitragotri S. Interactions of inertial cavitation bubbles with stratum corneum lipid bilayers during low-frequency sonophoresis. Biophys J 2003; 85: 3502-12

[250] Lavon I, Kost J. Ultrasound and transdermal drug delivery. Drug Discov Today 2004; 9: 670-6.

[251] Mitragotri S, Blankschtein D, Langer R. Ultrasound-mediated transdermal protein delivery. Science 1995; 269: 850-3.

[252] Park EJ, Werner J, Smith NB. Ultrasound Mediated Transdermal Insulin Delivery in Pigs Using a Lightweight Transducer. Pharm Res 2007. In Press.

[253] Singer AJ, Homan CS, Church AL, McClain SA. Low-frequency sonophoresis: pathologic and thermal effects in dogs. Acad Emerg Med 1998; 5: 35-40.

[254] Barry BW. Novel mechanisms and devices to enable successful transdermal drug delivery. Eur J Pharm Sci 2001; 14: 101-14.

[255] Batheja P, Thakur R, Michniak B. Transdermal iontophoresis. Expert Opin Drug Deliv 2006; 3: 127-38.

[256] Kalia YN, Naik A, Garrison J, Guy RH. Iontophoretic drug delivery. Adv Drug Deliv Rev 2004; 56: 619-58.

[257] Wang Y, Thakur R, Fan Q, Michniak B. Transdermal iontophoresis: combination strategies to improve transdermal iontophoretic drug delivery. Eur J Pharm Biopharm 2005; 60: 179-91.

[258] Dixit N, Bali V, Baboota S, Ahuja A, Ali J. Iontophoresis - an approach for controlled drug delivery: a review. Curr Drug Deliv 2007 4: $1-10$.

[259] Li GL, de Vries JJ, van Steeg TJ, van den Bussche H, Maas HJ, Reeuwijk HJ, et al. Transdermal iontophoretic delivery of apomorphine in patients improved by surfactant formulation pretreatment. J Control Release 2005; 101: 199-208.

[260] Nugroho AK, Li GL, Danhof M, Bouwstra JA. Transdermal iontophoresis of rotigotine across human stratum corneum in vitro: influence of $\mathrm{pH}$ and $\mathrm{NaCl}$ concentration. Pharm Res 2004; 21 : 844-50.

[261] Merino V, Lopez A, Kalia YN, Guy RH. Electrorepulsion versus electroosmosis: effect of $\mathrm{pH}$ on the iontophoretic flux of 5fluorouracil. Pharm Res 1999; 16: 758-61.

[262] Lopez RF, Bentley MV, Delgado-Charro MB, Guy RH. Iontophoretic delivery of 5-aminolevulinic acid (ALA): effect of $\mathrm{pH}$. Pharm Res 2001; 18: 311-5.

[263] Bain KT. A patient-activated iontophoretic transdermal system for acute pain management with fentanyl hydrochloride: overview and applications. J Opioid Manag 2006; 2: 314-24.

[264] Doliwa A, Santoyo S, Ygartua P. Transdermal lontophoresis and skin retention of piroxicam from gels containing piroxicam: hydroxypropyl-beta-cyclodextrin complexes. Drug Dev Ind Pharm 2001; 27: 751-8.

[265] Tiwari SB, Udupa N. Investigation into the potential of iontophoresis facilitated delivery of ketorolac. Int J Pharm 2003; 260: 93-103.

[266] Kanebako M, Inagi T, Takayama K. Transdermal delivery of indomethacin by iontophoresis. Biol Pharm Bull 2002; 25: 779-82.

[267] Al-Khalili M, Meidan VM, Michniak BB. Iontophoretic transdermal delivery of buspirone hydrochloride in hairless mouse skin. AAPS PharmSci 2003; 5: E14.

[268] Patel SR, Zhong H, Sharma A, Kalia YN. In vitro and in vivo evaluation of the transdermal iontophoretic delivery of sumatriptan succinate. Eur J Pharm Biopharm 2007; 66: 296-301.

[269] Rastogi SK, Singh J. Effect of chemical penetration enhancer and iontophoresis on the in vitro percutaneous absorption enhancement of insulin through porcine epidermis. Pharm Dev Technol 2005; 10: 97 104. 
[270] Pillai O, Panchagnula R. Transdermal iontophoresis of insulin. VI. Influence of pretreatment with fatty acids on permeation across rat skin. Skin Pharmacol Physiol 2004; 17: 289-97.

[271] Rastogi SK, Singh J. Passive and iontophoretic transport enhancement of insulin through porcine epidermis by depilatories: permeability and fourier transform infrared spectroscopy studies. AAPS PharmSciTech 2003; 4: E29.

[272] Nakamura K, Katagai K, Mori K, Higo N, Sato S, Yamamoto K. Transdermal administration of salmon calcitonin by pulse depolarization-iontophoresis in rats. Int J Pharm 2001; 218: 93-102.

[273] Suzuki Y, Iga K, Yanai S, Matsumoto Y, Kawase M, Fukuda T, et al. Iontophoretic pulsatile transdermal delivery of human parathyroid hormone (1-34). J Pharm Pharmacol 2001; 53: 1227-34.

[274] Heit MC, Monteiro-Riviere NA, Jayes FL, Riviere JE. Transdermal iontophoretic delivery of luteinizing hormone releasing hormone (LHRH): effect of repeated administration. Pharm Res 1994; 11: 1000-3.

[275] Nair V, Panchagnula R. Physicochemical considerations in the iontophoretic delivery of a small peptide: in vitro studies using arginine vasopressin as a model peptide. Pharmacol Res 2003; 48: 175-82.

[276] Schuetz YB, Naik A, Guy RH, Vuaridel E, Kalia YN. Transdermal iontophoretic delivery of vapreotide acetate across porcine skin in vitro. Pharm Res 2005; 22: 1305-12.

[277] Lau DT, Sharkey JW, Petryk L, Mancuso FA, Yu Z, Tse FL. Effect of current magnitude and drug concentration on iontophoretic delivery of octreotide acetate (Sandostatin) in the rabbit. Pharm Res 1994; 11: 1742-6.

[278] Leboulanger B, Fathi M, Guy RH, Delgado-Charro MB. Reverse iontophoresis as a noninvasive tool for lithium monitoring and pharmacokinetic profiling. Pharm Res 2004; 21: 1214-22.

[279] Power I. Fentanyl HCl iontophoretic transdermal system (ITS): clinical application of iontophoretic technology in the management of acute postoperative pain. Br J Anaesth 2007; 98: 4-11.

[280] Ghafourian T, Zandasrar P, Hamishekar H, Nokhodchi A. The effect of penetration enhancers on drug delivery through skin: a QSAR study. J Control Release 2004; 99: 113-25.

[281] Sung KC, Fang JY, Wang JJ, Hu OY. Transdermal delivery of nalbuphine and its prodrugs by electroporation. Eur J Pharm Sci 2003; 18: 63-70.

[282] Hu Q, Liang W, Bao J, Ping Q. Enhanced transdermal delivery of tetracaine by electroporation. Int J Pharm 2000; 202: 121-4.

[283] Wallace MS, Ridgeway B, Jun E, Schulteis G, Rabussay D, Zhang L. Topical delivery of lidocaine in healthy volunteers by electroporation, electroincorporation, or iontophoresis: an evaluation of skin anesthesia. Reg Anesth Pain Med 2001; 26: 229-38.

[284] Wang S, Kara M, Krishnan TR. Transdermal delivery of cyclosporinA using electroporation. J Control Release 1998; 50: 61-70.

[285] Conjeevaram R, Banga AK, Zhang L. Electrically modulated transdermal delivery of fentanyl. Pharm Res 2002; 19: 440-4.

[286] Prausnitz MR, Edelman ER, Gimm JA, Langer R, Weaver JC. Transdermal delivery of heparin by skin electroporation. Biotechnol 1995; 13: 1205-9.

[287] Medi BM, Singh J. Electronically facilitated transdermal delivery of human parathyroid hormone (1-34). Int J Pharm 2003; 263: 25-33.

[288] Dujardin N, Van Der Smissen P, Preat V. Topical gene transfer into rat skin using electroporation. Pharm Res 2001; 18: 61-6.

[289] Nir Y, Paz A, Sabo E, Potasman I. Fear of injections in young adults: prevalence and associations. Am J Trop Med Hyg 2003; 68: 341-4.

[290] Mitragotri S. Current status and future prospects of needle-free liquid jet injectors. Nat Rev Drug Discov 2006; 5: 543-8.

[291] Shergold OA, Fleck NA, King TS. The penetration of a soft solid by a liquid jet, with application to the administration of a needle-free injection. J Biomech 2006; 39: 2593-2602.

[292] Lindmayer I, Menassa K, Lambert J, Moghrabi A, Legendre L, Legault $\mathrm{C}$, et al. Development of new jet injector for insulin therapy. Diabetes Care 1986; 9: 294-7.

[293] Peter DJ, Scott JP, Watkins HC, Frasure HE. Subcutaneous lidocaine delivered by jet-injector for pain control before IV catheterization in the ED: The patients' perception and preference. Am J Emerg Med 2002; 20: 562-6.
[294] Zsigmond EK, Darby P, Koenig HM, Goll EF. Painless intravenous catheterization by intradermal jet injection of lidocaine: a randomized trial. J Clin Anesth 1999; 11: 87-94.

[295] Agerso H, Moller-Pedersen J, Cappi S, Thomann P, Jesussek B, Senderovitz T. Pharmacokinetics and pharmacodynamics of a new formulation of recombinant human growth hormone administered by ZomaJet 2 Vision, a new needle-free device, compared to subcutaneous administration using a conventional syringe. J Clin Pharmacol 2002; 42: 1262-8.

[296] Greenberg RS, Maxwell LG, Zahurak M, Yaster M. Preanesthetic medication of children with midazolam using the Biojector jet injector. Anesthesiology 1995; 83: 264-9.

[297] Saray Y, Gulec AT. Treatment of keloids and hypertrophic scars with dermojet injections of bleomycin: a preliminary study. Int J Dermatol 2005; $44:$ 777-84.

[298] Brodell RT, Bredle DL. The treatment of palmar and plantar warts using natural alpha interferon and a needleless injector. Dermatol Surg 1995; 21: 213-8.

[299] Suzuki T, Takahashi I, Takada G. Daily subcutaneous erythropoietin by jet injection in pediatric dialysis patients. Nephron 1995; 69: 347.

[300] Arora A, Hakim I, Baxter J, Rathnasingham R, Srinivasan R, Fletcher DA, et al. Needle-free delivery of macromolecules across the skin by nanoliter-volume pulsed microjets. Proc Natl Acad Sci USA 2007; 104: 4255-60.

[301] Burkoth TL, Bellhouse BJ, Hewson G, Longridge DJ, Muddle AG, Sarphie DF. Transdermal and transmucosal powdered drug delivery. Crit Rev Ther Drug Carrier Syst 1999; 16: 331-84.

[302] Mitchell P. UK biotech sector loses flagship PowderJect to Chiron. Nat Biotechnol 2003; 21: 717.

[303] Roberts LK, Barr LJ, Fuller DH, McMahon CW, Leese PT, Jones S. Clinical safety and efficacy of a powdered Hepatitis B nucleic acid vaccine delivered to the epidermis by a commercial prototype device. Vaccine 2005; 23: 4867-78.

[304] Dean HJ, Chen D. Epidermal powder immunization against influenza. Vaccine 2004; 23: 681-6.

[305] Wolf AR, Stoddart PA, Murphy PJ, Sasada M. Rapid skin anaesthesia using high velocity lignocaine particles: a prospective placebo controlled trial. Arch Dis Child 2002; 86: 309-12.

[306] Longridge DJ, Sweeney PA, Burkoth TL, Bellhouse BJ. Effects of particle size and cylinder pressure on dermal powderject delivery of testosterone to conscious rabbits. Proc Int Symp Control Rel Bioact Mat 1998; 25: 964.

[307] Benedek K, Walker E, Doshier LA, Stout R. Studies on the use of needle-free injection device on proteins. J Chromatogr A 2005; 1079: 397-407.

[308] Houtzagers CM, Visser AP, Berntzen PA, Heine RJ, van der Veen EA. The Medi-Jector II: efficacy and acceptability in insulindependent diabetic patients with and without needle phobia. Diabet Med 1988; 5: 135-8.

[309] Schneider U, Birnbacher R, Schober E. Painfulness of needle and jet injection in children with diabetes mellitus. Eur J Pediatr 1994; 153: 409-10.

[310] Lee S, McAuliffe DJ, Mulholland SE, Doukas AG. Photomechanical transdermal delivery of insulin in vivo. Lasers Surg Med 2001; 28: 282-5.

[311] Shomaker TS, Zhang J, Love G, Basta S, Ashburn MA. Evaluating skin anesthesia after administration of a local anesthetic system consisting of an S-Caine patch and a controlled heat-aided drug delivery (CHADD) patch in volunteers. Clin J Pain 2000; 16: 200-4.

[312] Shomaker TS, Zhang J, Ashburn MA. A pilot study assessing the impact of heat on the transdermal delivery of testosterone. J Clin Pharmacol 2001; 41: 677-82.

[313] Murthy SN. Magnetophoresis: an approach to enhance transdermal drug diffusion. Pharmazie 1999; 54: 377-9.

[314] Meehan E, Gross Y, Davidson D, Martin M, Tsals I. A Microinfusor Device for the Delivery of Therapeutic Levels of Peptides and Macromolecules. J Control Release. 1996; 46: 107-16.

[315] Wu XM, Todo H, Sugibayashi K. Enhancement of skin permeation of high molecular compounds by a combination of microneedle pretreatment and iontophoresis. J Cont Rel 2007; 118: 189-95. 